\title{
Differential pressure dependence of the complex conductivity of sandstones
}

\author{
A. Revil, ${ }^{1}$ A. Ghorbani, ${ }^{2}$ C. Mapeli, ${ }^{3}$ K. Livo $^{3}$ and M. Prasad $^{3}$ \\ ${ }^{1}$ Univ. Grenoble Alpes, Univ. Savoie Mont Blanc, CNRS, IRD, IFSTTAR, ISTerre, 38000 Grenoble, France. E-mail: andre.revil@univ-smb.fr \\ ${ }^{2}$ Department of Mining and Metallurgical Engineering, Yazd University, Yazd, Iran \\ ${ }^{3}$ Department of Petroleum Engineering, Colorado School of Mines, Golden, CO, USA
}

Accepted 2019 September 17. Received 2019 September 15; in original form 2019 May 8

\begin{abstract}
S UMMAR Y
An experimental work is undertaken to understand the effect of the differential pressure (in the range 3-20.7 MPa) upon the complex conductivity of sedimentary rocks. We use five sandstone core samples from outcrops and a sandstone analog built from sintered glass beads. The spectra were fitted with a Cole-Cole complex conductivity model and the four Cole-Cole parameters were plotted as a function of the differential stress (in the range 3-20.7 MPa). The Cole-Cole relaxation times are analysed in terms of the evolution of the pore size with the differential pressure. Neither the relaxation time nor the Cole-Cole exponent show a strong dependence with the differential pressure indicating that the distribution of the relaxation times remains here roughly the same when the differential stress increases. More specifically, the Cole-Cole exponent does not describe the entire distribution of relaxation times, but the broadness of this distribution. Since the relaxation times are related to the pore sizes, this means that the pore sizes do not depend on the differential pressure in this case. The chargeability is essentially independent of the differential pressure and close to the upper value that can be reached in rocks without metallic particles. This also means that the conductivity of these rocks is dominated by their surface conductivity contribution considering the low pore water salinity used in this work. These results are interpreted thanks to the Stern layer polarization model. The Stern layer denotes the inner part of the electrical double layer coating the surface of the grains. The predictions of this model are mostly consistent with the data.
\end{abstract}

Key words: Electrical properties; Permeability and porosity; Hydrogeophysics.

\section{INTRODUCTION}

Induced polarization has become a key method in hydrogeophysics to map a number of key properties of the subsurface (e.g. Binley et al. 2015) including permeability (Weller et al., 2010, 2015; Robinson et al. 2018) and pore throat sizes (Scott \& Barker 2003; Weller et al. 2016). These developments have been possible thanks to a better understanding of the underlying mechanisms of polarization especially those associated with the polarization of the electrical double layer coating the surface of the mineral grains (e.g. Vinegar \& Waxman 1984; Rosen \& Saville 1991; Rosen et al. 1993; Razilov \& Dukhin 1995; Revil et al. 2018a,b). In a sandstone, for instance, two main mechanisms have been proposed to date. They correspond to the polarization of the Stern layer of the non-metallic grains, especially clay minerals (e.g. Revil \& Florsch 2010) and the polarization of the metallic particles themselves especially pyrite and magnetite (Revil et al. 2015a,b). Other mechanisms such as membrane polarization (Bücker \& Hördt 2013a,b) and induced diffuse layer polarization are usually negligible (see Revil et al. 2018a,b for an extensive discussion on this controversial topic).
In this paper, for the sake of simplicity, we will consider sandstones and we will focus on the prediction of the dynamic Stern layer model. Recently, Revil and co-workers have developed a series of experiments to look at the effect of cation exchange capacity (Revil et al. 2018b), freezing (Duvillard et al. 2018) and salinity (Niu et al. 2016) to test further the predictions of this model. To date, we have found that this model is robust in explaining all the observed data. One of the new challenges with the time-lapse induced polarization is to test the potential ability of this method to monitor the microstructure of porous media undergoing deformation. We are interested to model the effect of the differential pressure upon the complex conductivity of sandstones. Our goal is both to understand how induced polarization can be used to monitor compaction of porous media and to further test the dynamic Stern layer model.

\section{THEORY}

\subsection{The dynamic Stern layer model}

We consider a sandstone made of insulating grains ( silicates and alu- 


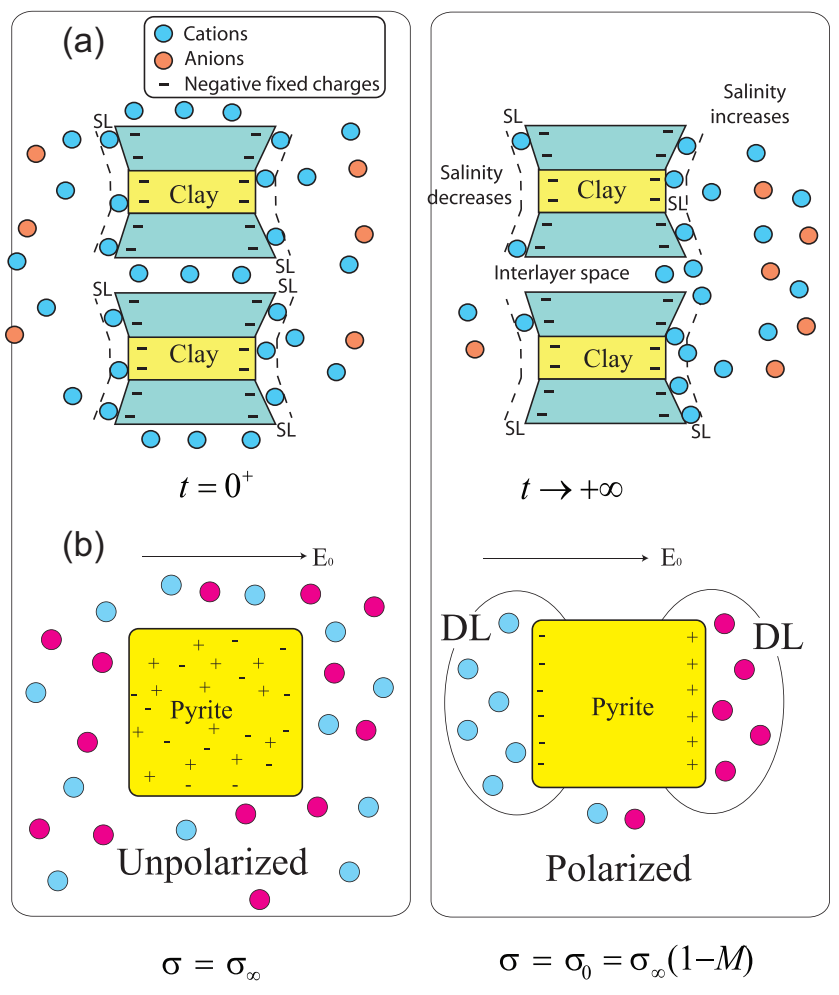

Figure 1. Polarization of clays and pyrite. (a) Clays possesses an electrical double layer cornposed of a Stern layer (SL) and a diffuse layer. Under the influence of an external electrical field $\mathbf{E}_{0}$, SL polarizes. The presence of a diffuse layer is responsible for the build-up of a salinity gradient around the particle. (b) Polarization of pyrite. The accumulation/depletion of the charges carriers inside the grain (delocalized electrons and p-holes) polarize the grain giving then rise to the formation of field induced diffuse layers (DL) around the grain. The first column defined the instantaneous conductivity $\sigma_{\infty}$ (where all charges carriers participate in the conduction process) while the second column defines the dc conductivity $\sigma_{0}$ (part of charges are no more available for conduction). The dc conductivity is always smaller than the instantaneous conductivity.

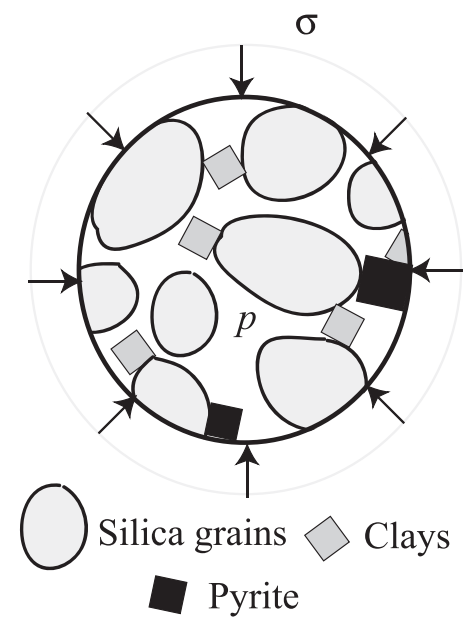

Figure 2. The porous material is made of silica grains with clay minerals. It is submitted to a confining stress $\sigma$ and a pore fluid pressure $p$. The application of the differential stress does not changer the cation exchange capacity or the specific surface area of the material. It has however an effect on the porosity and the formation factor. Our goal is to understand how the compaction of the porous material is affected by the differential stress in a clayey sandstone that may eventually contains also some pyrite. The polarization mechanisms of the clay and pyrite grains are shown in Fig. 1. minosilicates) coated by an electrical double layer and an harmonic electric field $\mathbf{E}=\mathbf{E}_{0} \exp (+\mathrm{i} \omega t)$ is applied to this porous material. According to Revil et al. (2017), the complex conductivity of the sandstone is written as

$\sigma^{*}(\omega)=\sigma_{\infty}-M_{n} \int_{0}^{\infty} \frac{h(\tau)}{1+(\mathrm{i} \omega \tau)^{1 / 2}} \mathrm{~d} \tau+\mathrm{i} \omega \varepsilon_{\infty}$,

where $\varepsilon_{\infty}$ (in $\mathrm{F} \mathrm{m}^{-1}$ ) denotes the permittivity associated, at high frequencies, with the Maxwell-Wagner polarization (or pure dielectric effects in absence of Maxwell-Wagner polarization), $\omega$ denotes the angular frequency $\left(\mathrm{rad} \mathrm{s}^{-1}\right), \sigma_{\infty}\left(\mathrm{S} \mathrm{m}^{-1}\right)$ denotes the instantaneous conductivity $\left(\mathrm{S} \mathrm{m}^{-1}\right), M_{n}=\sigma_{\infty}-\sigma_{0}\left(\mathrm{~S} \mathrm{~m}^{-1}\right)$ denotes the normalized chargeability defined as the difference between the instantaneous conductivity $\sigma_{\infty}$ and the direct current (dc) conductivity $\sigma_{0}$ $\left(\mathrm{S} \mathrm{m}^{-1}\right), \tau$ is a relaxation time (in s) and $h(\tau)$ denotes a (normalized) probability density (kernel) for the distribution of the time constants $\tau$ of the porous material. In turn, this distribution can be related to the distribution of polarization length scales (Revil \& Florsch 2010). We use below the subscript ' 0 " and ' $\infty$ ' to describe the (low frequency) dc and instantaneous (high frequency) conductivity, respectively, since in frequency-domain, they also correspond to the low and high-frequency limits of the (in-phase) conductivity, respectively. Their physics is explained in Fig. 1(a) in the context of the dynamic Stern layer model. In Fig. 1(b), we show the polarization of the pyrite particles that can be present in the sandstone. In this case, the polarization is due to polarization mechanisms inside and around the grains. Most of the sandstones considered in the present paper are however free of metallic particles.

If $h(\tau)$ is assumed to have a bell-shape in the form close to a lognormal distribution (see Cole-Cole 1941, their eq. (13) and their Fig. 9), eq. (1) can be approximated by a Cole-Cole model (Cole \& Cole 1941)

$\sigma^{*}(\omega)=\sigma_{\infty}-\frac{M_{n}}{1+\left(\mathrm{i} \omega \tau_{0}\right)^{c}}+\mathrm{i} \omega \varepsilon_{\infty}$

where the Cole-Cole exponent $c$ is usually comprised between 0 and 0.5 for rocks without metallic particles (Revil et al. 2014) and $\tau_{0}$ denotes the Cole-Cole relaxation time (corresponding to the peak of the relaxation time distribution). In the following, the experimental data will be fitted with a double Cole-Cole model to capture the effect of the Maxwell-Wagner polarization in addition to the low frequency polarization associated with the Stern layer polarization.

Expressions for the high and low frequency conductivities (i.e. $\sigma_{\infty}$ and $\sigma_{0}$ ) include a bulk component contribution (associated with the conductive pore water) and a surface conductivity contribution associated with the existence of the electrical double layer. With the exception of very low salinities, these two contributions act in parallel (e.g. Sen et al. 1988; Revil et al. 2018c). In absence of metallic particles, the instantaneous and dc conductivity are given by (Revil et al. 2017),

$\sigma_{\infty}=\frac{1}{F} \sigma_{w}+\left(\frac{1}{F \phi}\right) \rho_{g} B \mathrm{CEC}$,

$\sigma_{0}=\frac{1}{F} \sigma_{w}+\left(\frac{1}{F \phi}\right) \rho_{g}(B-\lambda) \mathrm{CEC}$,

and the resulting expression of the normalized chargeability is therefore,

$M_{n}=\left(\frac{1}{F \phi}\right) \rho_{g} \lambda \mathrm{CEC}$. 
Table 1. Properties of the core samples and pore water conductivity. Porosity and permeability were measured using a gas permeameter and porosimeter. The value on Table 1 are from the lowest pressure where they were measured. The grain density was determined from the XRD measurements provided by Hess from the mineral composition. The pore water conductivity was measured using a conductivity meter (Thermo Fisher Scientific PH/conductivity multiparameter benchtop meter).

\begin{tabular}{|c|c|c|c|c|}
\hline Sample & $\begin{array}{l}\text { Porosity } \\
\text { (per cent) }\end{array}$ & Permeability (mD) & $\begin{array}{c}\text { Grain density (kg } \\
\mathrm{m}^{-3} \text { ) }\end{array}$ & $\begin{array}{c}\text { Pore water } \\
\text { conductivity }\left(\mathrm{S} \mathrm{m}^{-1}\right)\end{array}$ \\
\hline BB-H3 Berea (Buff) Sandstone & 17.7 & 240 & 2640 & 0.1200 \\
\hline BR-H2 Berea Sandstone & 20.3 & 216 & 2650 & 0.1320 \\
\hline CT-H1 Carbon Tan Sandstone & 16.4 & 62 & 2650 & 2.76 \\
\hline NU-H2 Nugget Sandstone & 15.0 & 125 & 2630 & 0.1225 \\
\hline 100u-GB Glass bead sandstone & 31.0 & 11900 & - & 0.1262 \\
\hline
\end{tabular}

Table 2. Mineralogy (through X-ray diffraction analysis). Mass fraction of the solid phase.

\begin{tabular}{lcccc}
\hline Sample & Silica & Feldspar & Carbon & Clay \\
\hline BB-H3 & 0.861 & 0.053 & 0.007 & 0.079 \\
BR-H2 & 0.852 & 0.057 & 0.015 & 0.007 \\
CG-H3 & 0.900 & 0.038 & 0.076 & 0.055 \\
CT-H1 & 0.877 & 0.013 & 0.006 & 0.034 \\
NU-H2 & 0.886 & 0.061 & 0.047 \\
\hline
\end{tabular}

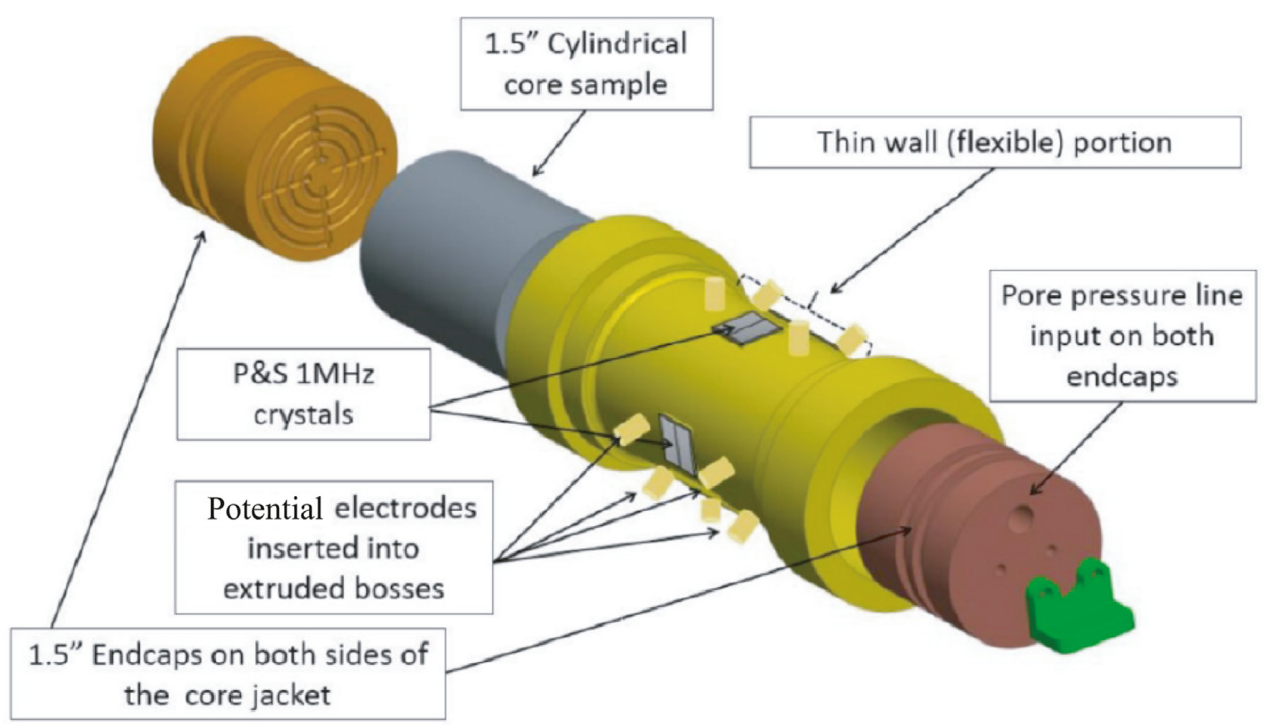

Figure 3. Sample holder used to measure the low frequency electrical conductivity using the four electrodes method (two current electrodes at the end faces of the core sample and two voltage electrodes on its side). The sample holder is also used to insulate the core sample from the confining fluid but allows fluid flow at the end faces of the core sample and pore pressure to be applied. P\&S refer to the piezoelectrical crystals that vibrate to create compressional and shear waves for the acoustic experiments as P-crystal and S-crystal for the compressional and shear waves at $1 \mathrm{MHz}$.

We can also choose to report the result in terms of chargeability $M=\left(\sigma_{\infty}-\sigma_{0}\right) / \sigma_{\infty}$ as discussed further below. In these equations, $\sigma_{w}$ (in $\mathrm{S} \mathrm{m} \mathrm{m}^{-1}$ ) denotes the pore water conductivity (which depends on salinity and temperature), $F$ (dimensionless) the intrinsic formation factor related to the porosity by the first Archie's law $F=\phi^{-\mathrm{m}}$ where $m$ (dimensionless) is called the first Archie exponent or porosity exponent (Archie 1942), $\phi$ denotes the connected porosity (dimensionless), $\rho_{g}$ is the grain density (in $\mathrm{kg} \mathrm{m}^{-3}$, usually $\rho_{g}=2650 \mathrm{~kg} \mathrm{~m}^{-3}$ ), CEC is the cation exchange capacity (in $\mathrm{C} \mathrm{kg}^{-1}$ and often expressed in meq/100 $\mathrm{g}$ with $\left.1 \mathrm{meq} / 100 \mathrm{~g}=963.20 \mathrm{C} \mathrm{kg}^{-1}\right), B\left(\right.$ in $\mathrm{m}^{2} \mathrm{~s}^{-1} \mathrm{~V}^{-1}$ ) denotes the apparent mobility of the counterions for surface conduction and $\lambda$ (in $\mathrm{m}^{2} \mathrm{~s}^{-1} \mathrm{~V}^{-1}$ ) denotes the apparent mobility of the counterions for the polarization associated with the quadrature conductivity (Revil et al. 2017, and references therein). A dimensionless number $\mathrm{R}$ is also introduced by $\mathrm{R}=\lambda / B$ (see Revil et al. 2017 , for further explanations). From our previous studies (e.g. Ghorbani et al. 2018), we have $B\left(\mathrm{Na}^{+}, 25^{\circ} \mathrm{C}\right)=3.1 \pm 0.3 \times 10^{-9} \mathrm{~m}^{-2} \mathrm{~s}^{-1} \mathrm{~V}^{-1}$ and $\lambda\left(\mathrm{Na}^{+}, 25{ }^{\circ} \mathrm{C}\right)=3.0 \pm 0.7 \times 10^{-10} \mathrm{~m}^{-2} \mathrm{~s}^{-1} \mathrm{~V}^{-1}$, and $R$ is typically around $0.09 \pm 0.01$ (independent of the temperature and saturation). The dimensionless number $R$ appears to be a fundamental parameter to characterize polarization. Note that when surface 

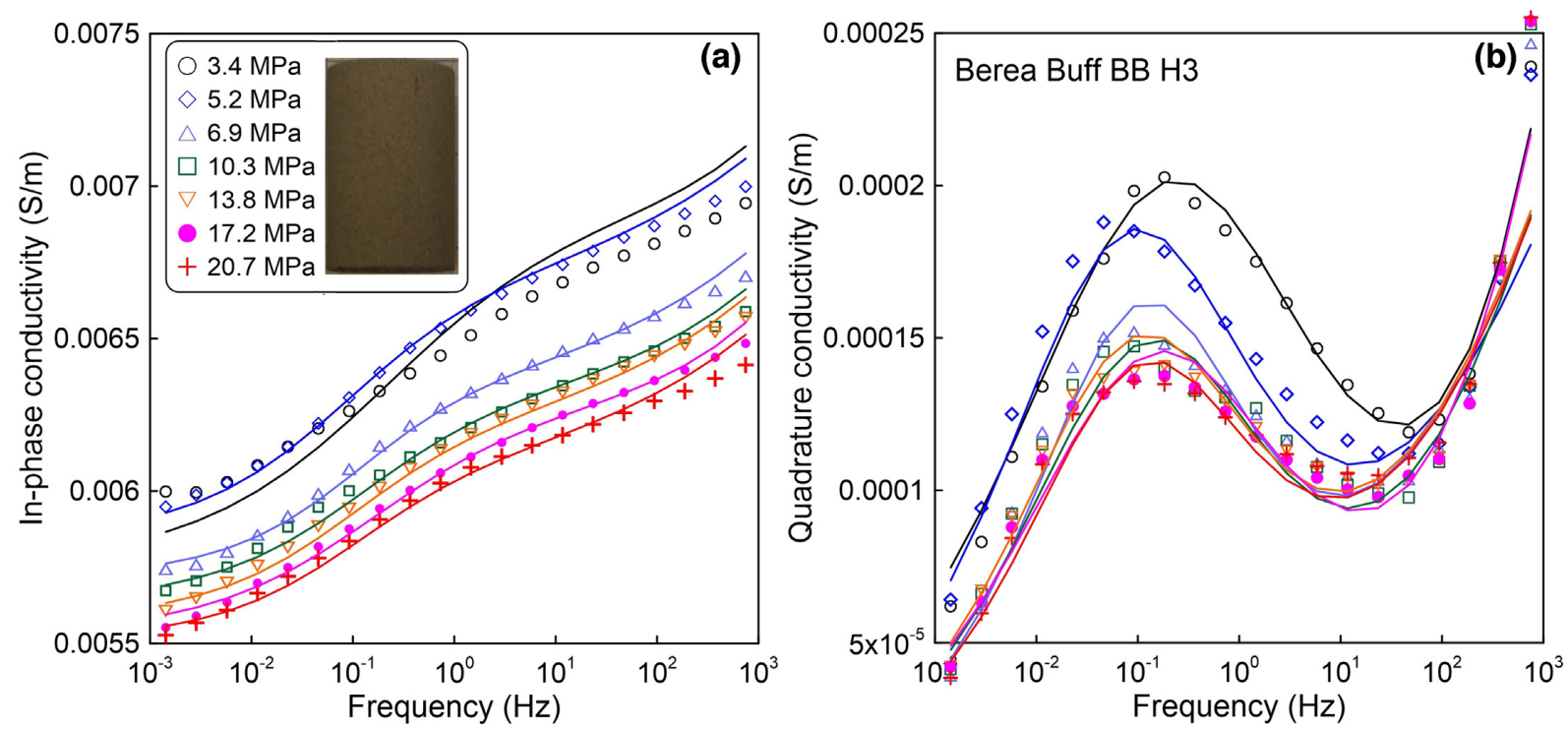

Figure 4. Sample Berea Buff BB-H3. (a) In-phase conductivity. (b) Quadrature conductivity. This sandstone is characterized by a well-defined peak. The plain lines correspond to the fit of the data using the parametric model developed in Appendix B.
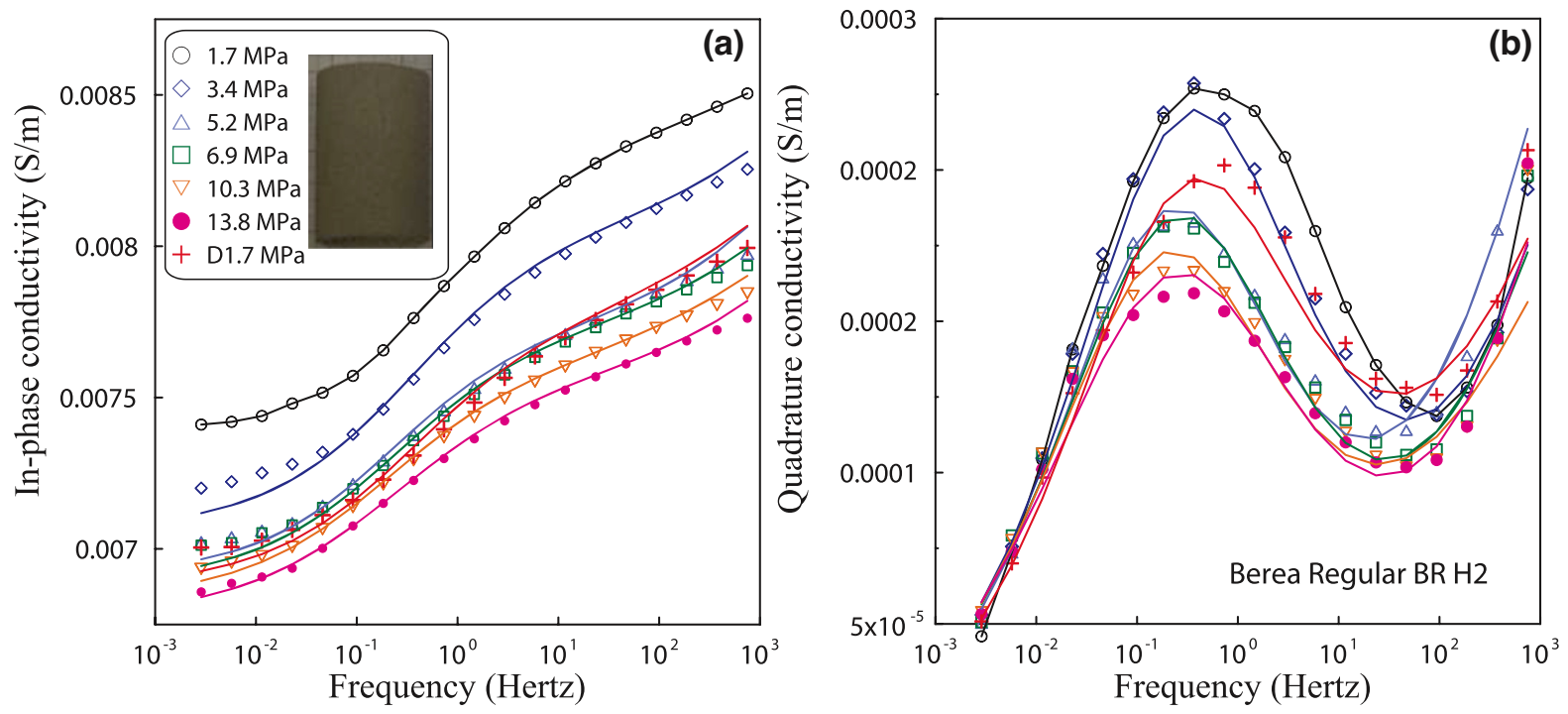

Figure 5. Sample Berea Regular BR-H2. (a) In-phase conductivity. (b) Quadrature conductivity. This sandstone is characterized by a well-defined peak. The plain lines correspond to the fit of the data using the parametric model developed in Appendix B.

conductivity dominates the conductivity response and in absence of metallic particles, we have:

$\lim _{\sigma_{S}^{\infty}>>\sigma_{w} / F} \frac{M_{n}}{\sigma_{\infty}}=\frac{\lambda}{B}=R \approx 0.09$.

In other words, if we plot the normalized chargeability as a function of the conductivity, the two parameters can be fitted by a linear relationship with a slope of $R$ when surface conductivity is the dominant conduction mechanism.

We connect now the relaxation times to the pore sizes in the context of the Stern-layer polarization model. First, for granular materials, the relaxation time depends on the grain size, but it is well-accepted that grain sizes and pore sizes are interrelated. Consequently having a relationship between the relaxation times and the grain sizes implies ipse facto a relationship between the relaxation times and the pore sizes. The second way to explain a connection between the pore sizes and the grain sizes is that the relaxation time is related to the radius of curvature of the solid-water interface and therefore a connection between the relaxation time and the pore size can be expected as discussed in details by Niu \& Revil (2016). The relaxation time of the Cole-Cole model $\tau_{0}$ can be related to the mean pore size by,

$\tau_{0}=\frac{\Lambda^{2}}{2 D_{(+)}^{S}}$,

with $D_{(+)}^{S}=15 \times 10^{-12} \mathrm{~m}^{2} \mathrm{~s}^{-1}$ (equivalent to a mobility for the counterions of $5.8 \times 10^{-10} \mathrm{~m}^{2} \mathrm{~s}^{-1} \mathrm{~V}^{-1}$ ) and where $\Lambda$ (in $\mathrm{m}$ ) denotes a characteristic pore size of the porous material (see Revil et al. 

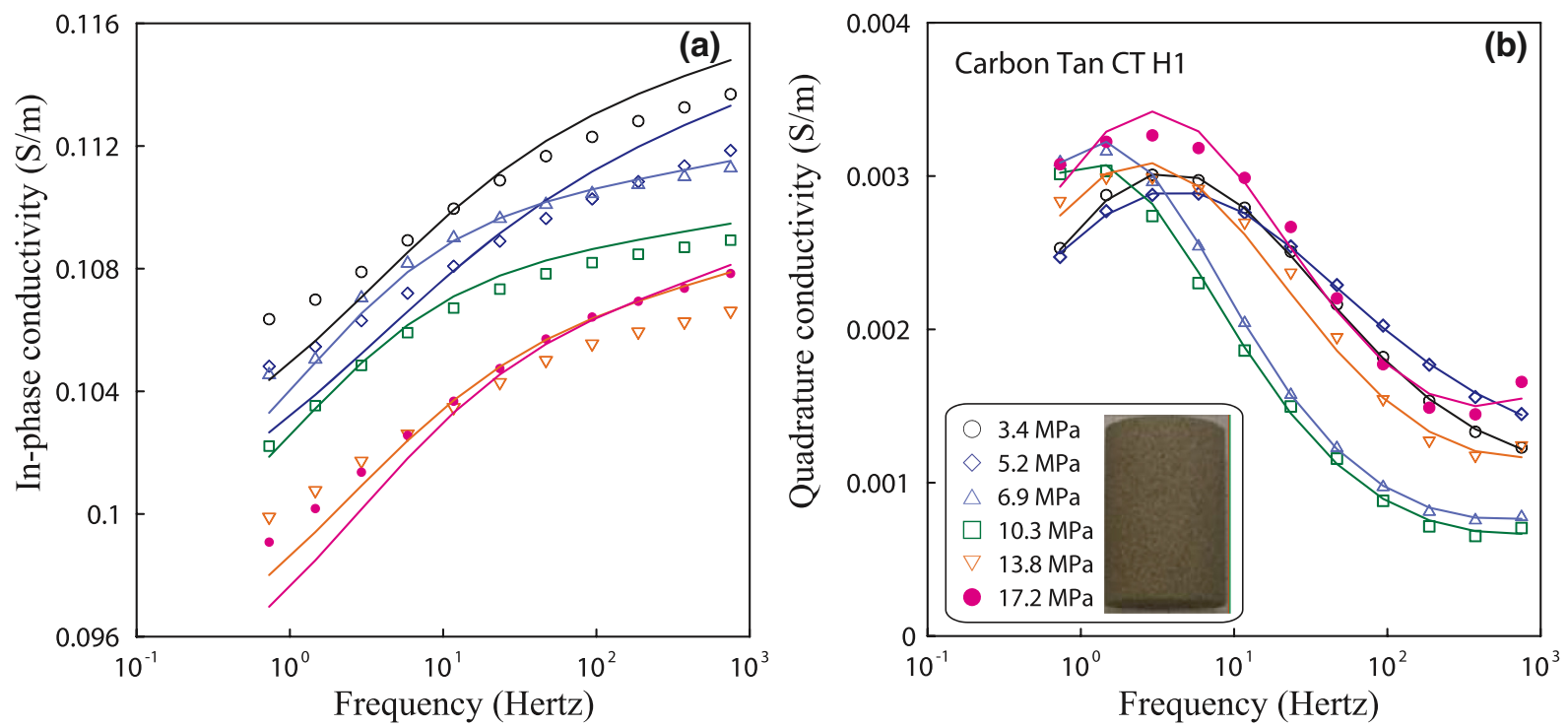

Figure 6. Sample Carbon Tan CT-H1. (a) In-phase conductivity. (b) Quadrature conductivity. This sandstone is characterized by a well-defined peak. The plain lines correspond to the fit of the data using the parametric model developed in Appendix B.
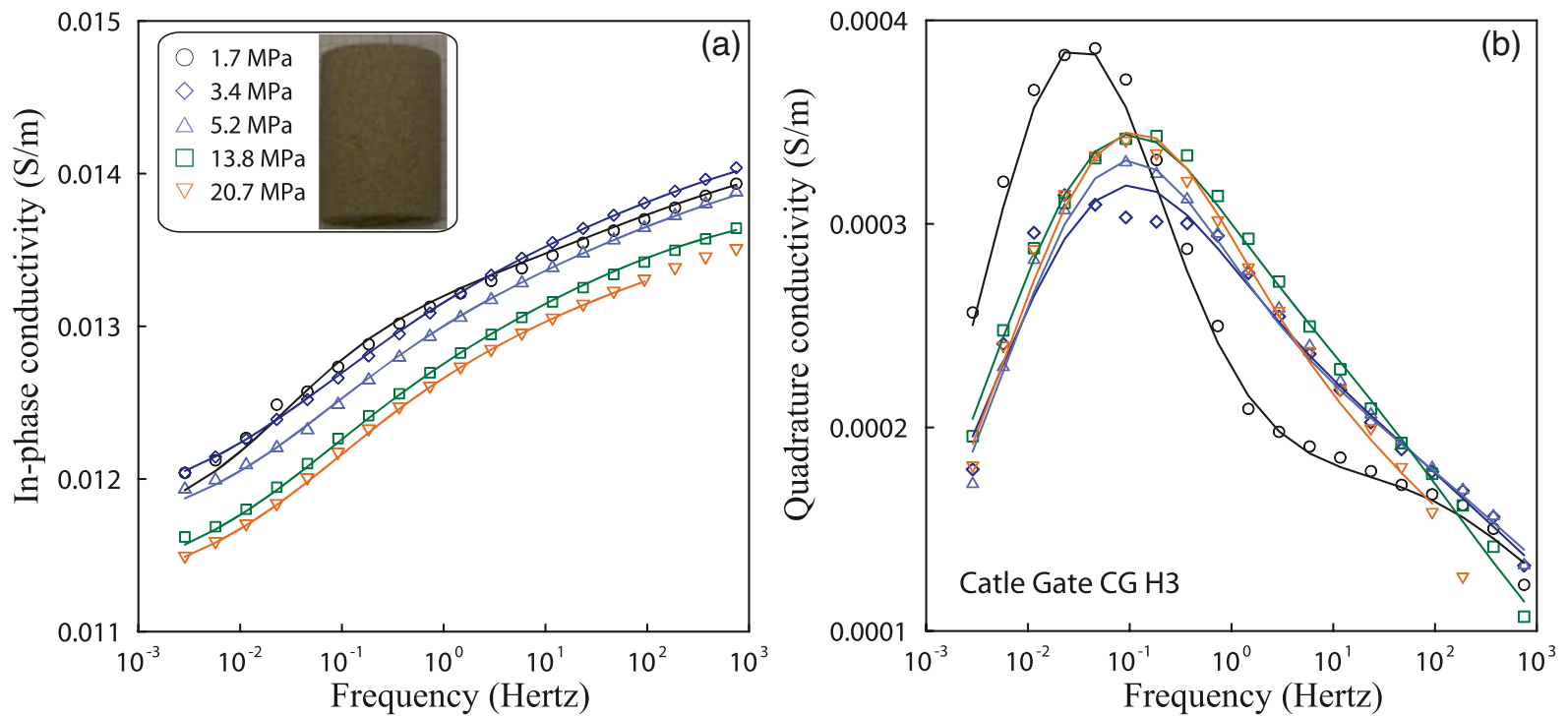

Figure 7. CatleGate CG-H3 core sample. (a) In-phase conductivity. (b) Quadrature conductivity. This sandstone is characterized by a well-defined peak. The plain lines correspond to the fit of the data using the parametric model developed in Appendix B.

2012). Since according to eq. (7) the relaxation time is associated with the pore size, this implies that the broadness of the distribution of the relaxation times, hence $c$, is related to the broadness of the distribution of the pore sizes.

In order to complete the unification of the induced polarization theory in terms of relationships between its fundamental parameters, Revil et al. (2017) recently developed a quantitative relationship between the normalized chargeability and the quadrature conductivity. This relationship is not based on the dynamic Stern layer model but on the causality principle that can be used to consistently model the in-phase and quadrature conductivities. Strictly speaking, the following relationships have been derived assuming that the distribution of the relaxation times $h(\tau)$ is broad enough (so the spectra are rather flat). That said, we have observed that these relationships works even for well-sorted materials exhibiting a clear peak in their quadrature conductivity. Under these assumptions, the following linear relationship can be derived between the quadrature conductivity (measured at the geometric mean of two frequencies $f_{1}$ and $f_{2}$ ) and the normalized chargeability defined as the difference between the in-phase conductivity at frequency $f_{2}>f_{1}$ and the in-phase conductivity at the frequency $f_{1}$ :

$\sigma^{\prime \prime}\left(\sqrt{f_{1} f_{2}}\right) \approx-\frac{M_{n}\left(f_{1}, f_{2}\right)}{\alpha}=-\frac{\sigma^{\prime}\left(f_{2}\right)-\sigma^{\prime}\left(f_{1}\right)}{\alpha}$.

The value of $\alpha$ is determined using Drakes's model also called the constant phase model (see Van Voorhis et al. 1973; Börner 1992) 

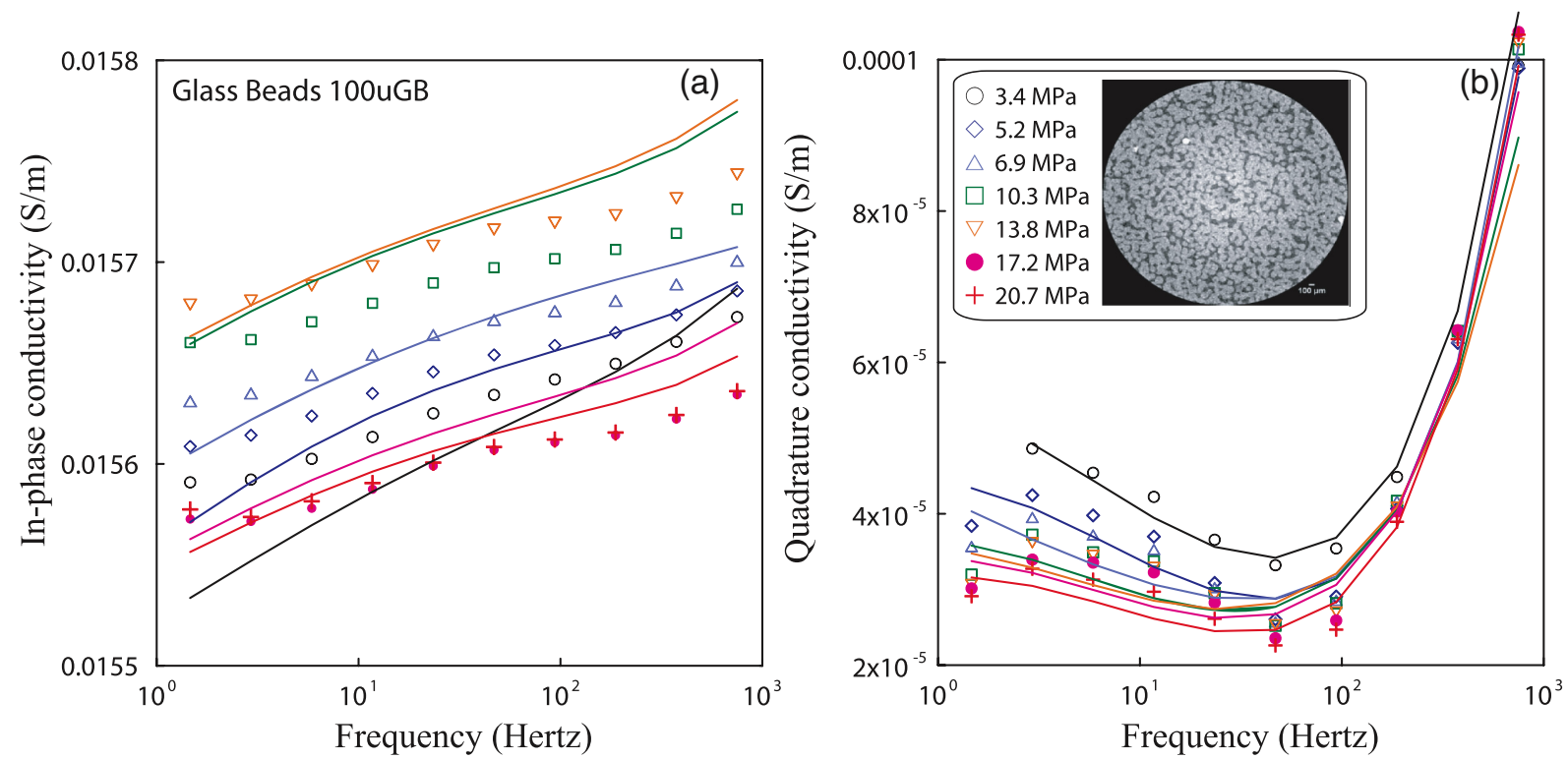

Figure 8. Sample Glass Beads 100u-GB. (a) In-phase conductivity. (b) Quadrature conductivity. The peak of the quadrature conductivity is at too low frequencies to be correctly observed. The plain lines correspond to the fit of the data using the parametric model developed in Appendix B.
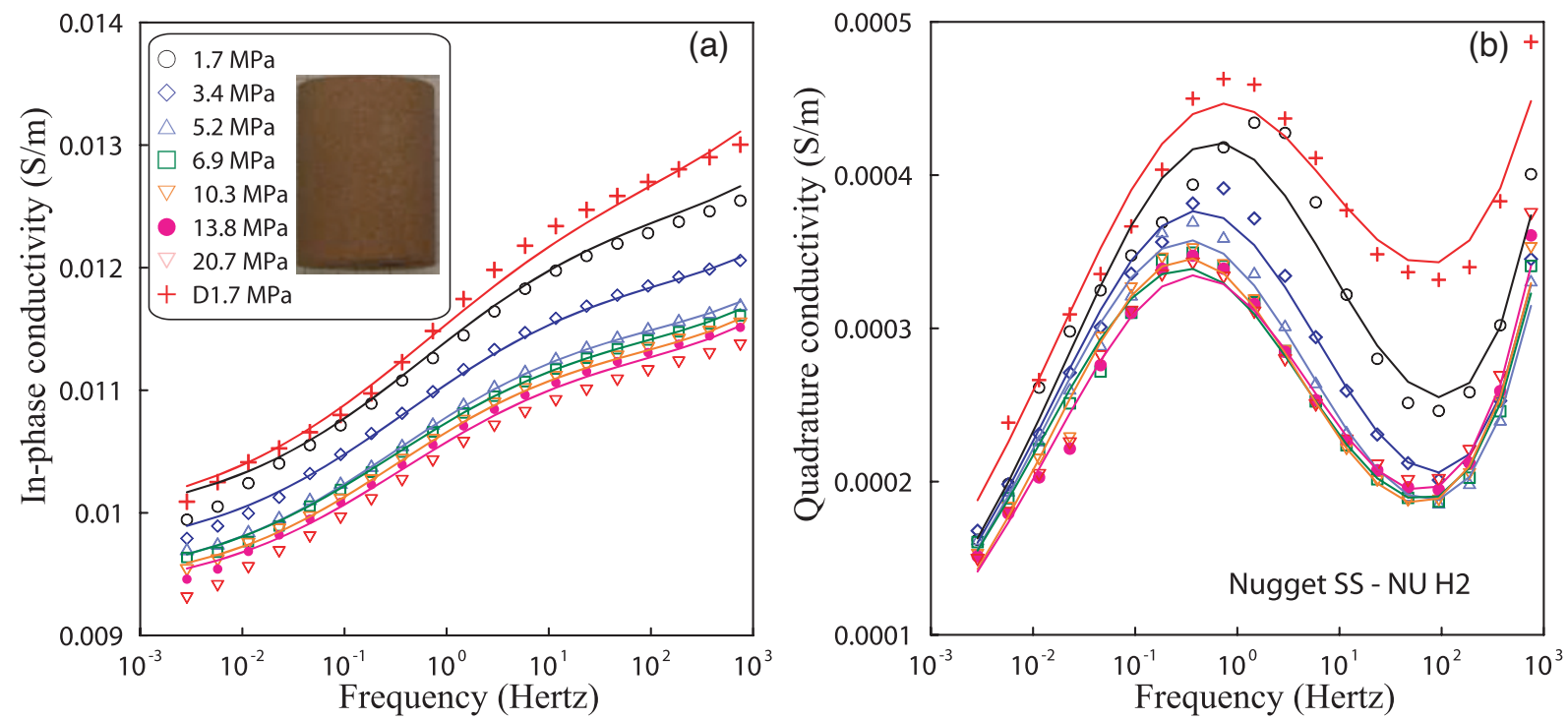

Figure 9. Sample Nugget SS-NU H2. (a) In-phase conductivity. (b) Quadrature conductivity. The peak of the quadrature conductivity is at too low frequencies to be observed. The plain lines correspond to the fit of the data using the parametric model developed in Appendix B.

Table 3. Cole-Cole parameters for sample 100u-GB.

\begin{tabular}{lcccccccc}
\hline$P_{d}(\mathrm{MPa})$ & $\sigma_{\infty}\left(\mathrm{S} \mathrm{m}^{-1}\right)$ & $M_{1}(-)$ & $M_{2}(-)$ & $c_{1}(-)$ & $c_{2}(-)$ & $\tau_{1}(\mathrm{~s})$ & $\tau_{2}(\mathrm{~s})$ \\
\hline 3.4 & 0.0238 & 0.013 & 0.338 & 0.427 & 0.821 & 0.252 & $1.04 \mathrm{E}-06$ \\
5.2 & 0.0180 & 0.014 & 0.131 & 0.436 & 0.857 & 0.207 & $4.97 \mathrm{E}-06$ \\
6.9 & 0.0201 & 0.011 & 0.219 & 0.434 & 0.781 & 0.232 & $1.55 \mathrm{E}-06$ \\
10.3 & 0.0209 & 0.010 & 0.246 & 0.419 & 0.746 & 0.226 & $9.62 \mathrm{E}-07$ \\
13.8 & 0.0192 & 0.012 & 0.180 & 0.386 & 0.717 & 0.306 & 1.306 \\
17.2 & 0.0204 & 0.010 & 0.233 & 0.405 & 0.808 & 0.209 & 1.348 \\
20.7 & 0.0176 & 0.010 & 0.113 & 0.428 & 0.879 & 0.151 & $6.861 \mathrm{E}-06$ \\
\hline
\end{tabular}


Table 4. Cole-Cole parameters for sample BB_H3.

\begin{tabular}{lcccccccc}
\hline$P_{d}(\mathrm{MPa})$ & $\sigma_{\infty}\left(\mathrm{S} \mathrm{m}^{-1}\right)$ & $M_{1}(-)$ & $M_{2}(-)$ & $c_{1}(-)$ & $c_{2}(-)$ & $\tau_{1}(\mathrm{~s})$ & $\begin{array}{c}\text { RMS } \\
\tau_{2}(\mathrm{~s})\end{array}$ \\
\hline 3.4 & 0.010 & 0.121 & 0.294 & 0.410 & 0.495 & 0.737 & $2.59 \mathrm{E}-06$ \\
5.2 & 0.009 & 0.094 & 0.254 & 0.489 & 0.313 & 1.913 & $2.21 \mathrm{E}-06$ \\
6.9 & 0.009 & 0.075 & 0.260 & 0.544 & 0.328 & 1.478 & $3.27 \mathrm{E}-06$ \\
10.3 & 0.008 & 0.083 & 0.241 & 0.491 & 0.382 & 1.292 & $4.68 \mathrm{E}-06$ \\
13.8 & 0.009 & 0.086 & 0.299 & 0.451 & 0.466 & 1.052 & $3.55 \mathrm{E}-06$ \\
17.2 & 0.009 & 0.082 & 0.305 & 0.459 & 0.447 & 1.041 & $2.79 \mathrm{E}-06$ \\
20.7 & 0.009 & 0.088 & 0.313 & 0.393 & 0.439 & 1.301 & $2.44 \mathrm{E}-06$ & 0.903 \\
\hline
\end{tabular}

Table 5. Cole-Cole parameters for sample BR-H2.

\begin{tabular}{lcccccccc}
\hline$P_{d}(\mathrm{MPa})$ & $\sigma_{\infty}\left(\mathrm{S} \mathrm{m}^{-1}\right)$ & $M_{1}(-)$ & $M_{2}(-)$ & $c_{1}(-)$ & $c_{2}(-)$ & $\tau_{1}(\mathrm{~s})$ & $\tau_{2}(\mathrm{~s})$ & \multicolumn{2}{c}{ RMS } \\
\hline 1.7 & 0.0113 & 0.090 & 0.268 & 0.518 & 0.378 & 0.356 & $7.27 \mathrm{E}-07$ \\
3.4 & 0.0103 & 0.097 & 0.218 & 0.507 & 0.387 & 0.463 & $1.93 \mathrm{E}-06$ \\
5.2 & 0.0101 & 0.079 & 0.238 & 0.527 & 0.392 & 0.744 & $3.66 \mathrm{E}-06$ & 0.749 \\
6.9 & 0.0097 & 0.086 & 0.205 & 0.508 & 0.383 & 0.678 & $3.08 \mathrm{E}-06$ \\
10.3 & 0.0096 & 0.078 & 0.207 & 0.513 & 0.320 & 0.840 & $2.02 \mathrm{E}-06$ \\
13.8 & 0.0102 & 0.079 & 0.255 & 0.477 & 0.405 & 0.677 & $1.42 \mathrm{E}-06$ & 0.670 \\
\hline
\end{tabular}

Table 6. Cole-Cole parameters for sample CG-H3.

\begin{tabular}{|c|c|c|c|c|c|c|c|c|}
\hline$P_{d}(\mathrm{MPa})$ & $\sigma_{\infty}\left(\mathrm{S} \mathrm{m}^{-1}\right)$ & $M_{1}(-)$ & $M_{2}(-)$ & $c_{1}(-)$ & $c_{2}(-)$ & $\tau_{1}(\mathrm{~s})$ & $\tau_{2}(\mathrm{~s})$ & $\begin{array}{c}\text { RMS } \\
\text { (per cent) }\end{array}$ \\
\hline 1.7 & 0.0143 & 0.103 & 0.086 & 0.554 & 0.311 & 6.165 & $2.87 \mathrm{E}-03$ & 0.381 \\
\hline 5.2 & 0.0143 & 0.085 & 0.107 & 0.476 & 0.264 & 2.733 & $6.57 \mathrm{E}-03$ & 0.377 \\
\hline 13.8 & 0.0139 & 0.107 & 0.083 & 0.445 & 0.340 & 3.013 & $1.06 \mathrm{E}-02$ & 0.322 \\
\hline 20.7 & 0.0139 & 0.094 & 0.101 & 0.468 & 0.256 & 2.253 & $1.11 \mathrm{E}-02$ & 0.344 \\
\hline
\end{tabular}

Table 7. Cole-Cole parameters for sample CT-H1.

\begin{tabular}{|c|c|c|c|c|c|c|c|c|}
\hline$P_{d}(\mathrm{MPa})$ & $\sigma_{\infty}\left(\mathrm{S} \mathrm{m}^{-1}\right)$ & $M_{1}(-)$ & $M_{2}(-)$ & $c_{1}(-)$ & $c_{2}(-)$ & $\tau_{1}(\mathrm{~s})$ & $\tau_{2}(\mathrm{~s})$ & $\begin{array}{c}\text { RMS } \\
\text { (per cent) }\end{array}$ \\
\hline 3.4 & 0.128 & 0.105 & 0.110 & 0.505 & 0.248 & 0.047 & $1.35 \mathrm{E}-07$ & 0.186 \\
\hline 6.9 & 0.141 & 0.083 & 0.217 & 0.622 & 0.256 & 0.123 & $2.35 \mathrm{E}-09$ & 0.219 \\
\hline 10.3 & 0.131 & 0.089 & 0.174 & 0.604 & 0.263 & 0.143 & 4.32E-09 & 0.508 \\
\hline 13.8 & 0.148 & 0.092 & 0.278 & 0.525 & 0.340 & 0.067 & $1.20 \mathrm{E}-08$ & 0.571 \\
\hline 17.2 & 0.139 & 0.106 & 0.228 & 0.538 & 0.436 & 0.059 & $2.97 \mathrm{E}-07$ & 0.653 \\
\hline
\end{tabular}

Table 8. Cole-Cole parameters for sample NU-H2.

\begin{tabular}{lccccccc}
\hline$P_{d}(\mathrm{MPa})$ & $\sigma_{\infty}\left(\mathrm{S} \mathrm{m}^{-1}\right)$ & $M_{1}(-)$ & $M_{2}(-)$ & $c_{1}(-)$ & $c_{2}(-)$ & $\tau_{1}(\mathrm{~s})$ & $\begin{array}{c}\text { RMS } \\
\tau_{2}(\mathrm{~s})\end{array}$ \\
\hline 1.7 & 0.0192 & 0.141 & 0.342 & 0.381 & 0.629 & 0.274 & $2.12 \mathrm{E}-06$ \\
3.4 & 0.0172 & 0.139 & 0.301 & 0.387 & 0.657 & 0.401 & $3.15 \mathrm{E}-06$ \\
5.2 & 0.0169 & 0.131 & 0.312 & 0.396 & 0.636 & 0.493 & $2.71 \mathrm{E}-06$ \\
6.9 & 0.0159 & 0.134 & 0.274 & 0.391 & 0.609 & 0.542 & $3.63 \mathrm{E}-06$ \\
10.3 & 0.0153 & 0.134 & 0.253 & 0.412 & 0.603 & 0.514 & $4.82 \mathrm{E}-06$ \\
13.8 & 0.0157 & 0.131 & 0.277 & 0.395 & 0.620 & 0.445 & $4.22 \mathrm{E}-06$ \\
20.7 & 0.0149 & 0.139 & 0.247 & 0.387 & 0.660 & 0.450 & $7.47 \mathrm{E}-06$ \\
\hline
\end{tabular}

and is given in this case by:

$\alpha \approx \frac{2}{\pi} \ln A$,

where $A$ is the number of decades separating high and low frequencies (see Revil et al. 2017a for details). Typically, $\alpha$ is on the order of 8-9 in the case we consider very low and very high frequencies (for instance $10 \mathrm{mHz}$ and $10 \mathrm{kHz}, 4$ decades $A=10^{4}$, e.g.
Revil et al. 2018a) used to define $M_{n}=\sigma_{\infty}-\sigma_{0}$. If $\alpha$ is determined over two decades only (as done below between $10^{-2}$ and $1 \mathrm{~Hz}$, i.e. $A=10^{2}, \alpha=2.9$ ), it is therefore enough to use a correction factor of $\sim 3$ to determine, in this situation, the (cumulative) normalized chargeability that would be obtained by $M_{n}=\sigma_{\infty}-\sigma_{0}$ from the normalized chargeability that can be computed from measured the conductivity dispersion between $10^{-2}$ and $1 \mathrm{~Hz}$. 


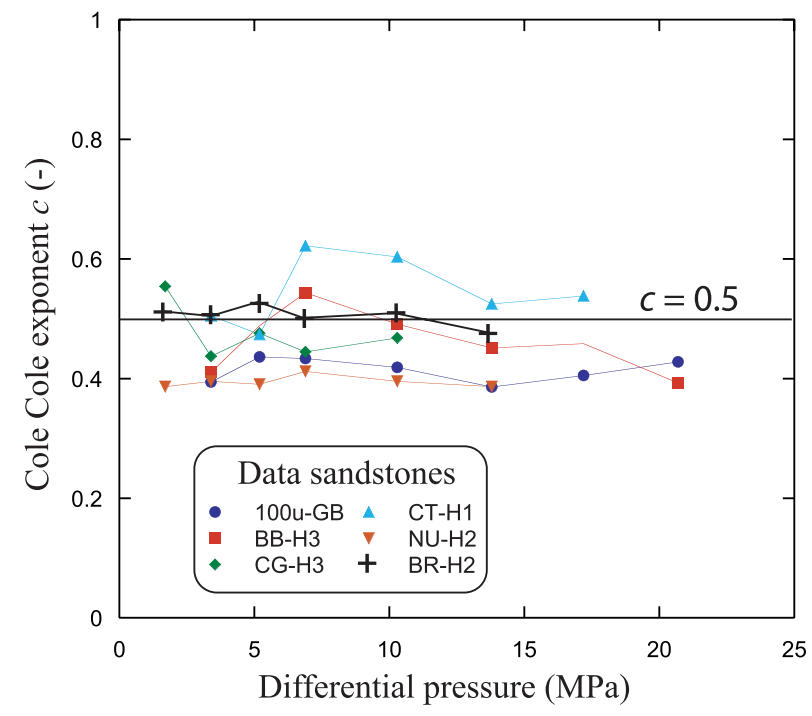

Figure 10. Evolution of the Cole-Cole exponent $c$ as a function of the differential pressure. We observe no specific trend indicating that all the pores controlling the relaxation time distribution seems to follow the same dependence with the differential pressure. The value of $c=0.5$ is typical of a narrow pore size distributions, which is in agreement with the NMR data

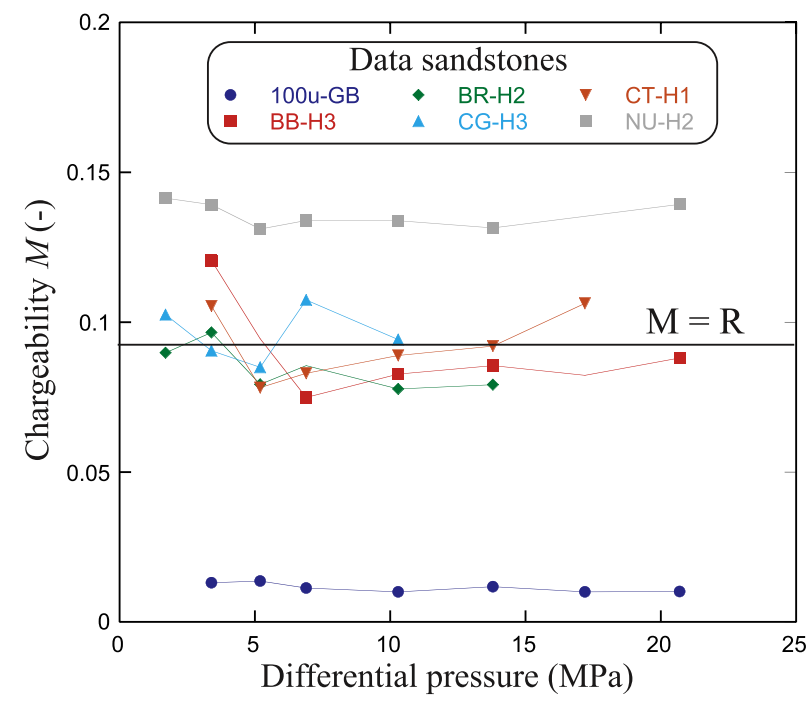

Figure 11. Evolution of the chargeability $M$ as a function of the differential pressure. We observe no specific trend. Sample NU-H2 has a chargeability above the maximum value allowed for metal-free sandstone, which means that it is likely to have pyrite. Samples BB-H3, BR-H2, CG-H3 and CT-H1 have reach the maximum value possible for metal free sandstones, which in turn implies that their conductivity is dominated by surface conduction. Sample 100u-GB has a very small chargeability indicating that its conductivity is dominated by the conduction through the bulk pore space. This is consistent with the fact that this sandstone is clay-free.

\subsection{Influence of the differential pressure}

Our goal in this paper is to better understand the role of the differential stress upon the complex conductivity of sandstones (Fig. 2). In order to capture the influence of the differential pressure, we need a constitutive equation connecting the porosity to the stress. We will use the following constitutive equation between the porosity $\phi$ and

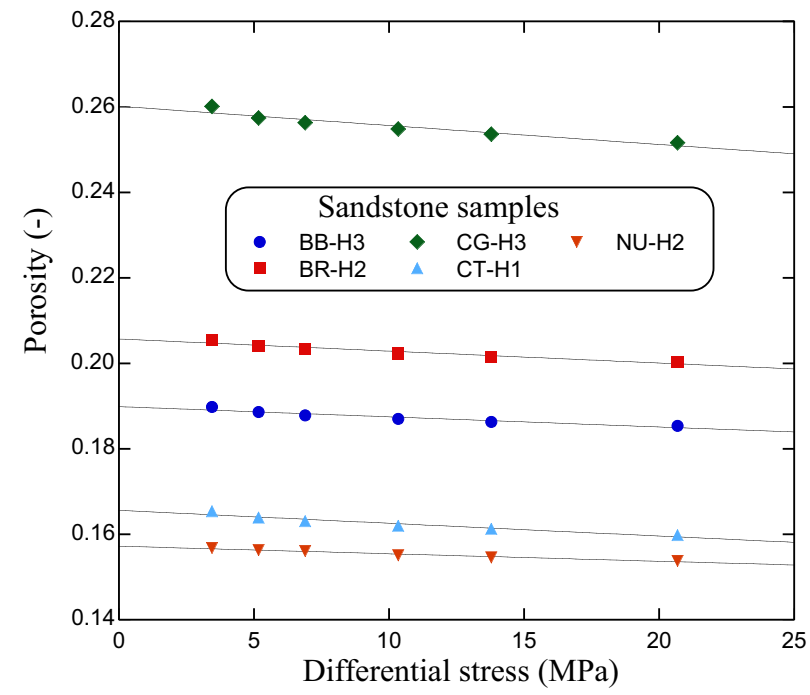

Figure 12. Evolution of the porosity $\phi$ as a function of the differential pressure (in MPa) showing the compaction of the sandstone. The plain lines correspond to the fit of the data with the porosity/differential stress constitutive relationship described in the main text. The two fitting parameters (initial porosity and compressibility coefficient) are reported in Table 10 . The compressibility coefficients are in the range $11 \times 10^{-10}$ to $19 \times 10^{-10}$ $\mathrm{Pa}^{-1}$.

the differential pressure $P_{d}=\sigma-p$ (Revil et al. 2002)

$\phi=\phi_{0} \exp \left(-\beta_{m} P_{d}\right)$,

where $\sigma$ is the confining stress $(\mathrm{Pa}), p$ the pore fluid pressure $(\mathrm{Pa})$, $\phi_{0}$ is the initial (reference) porosity (dimensionless), and $\beta_{m}$ is an apparent compressibility of the pore space in $\mathrm{Pa}^{-1}$. Since damage occurs, the deformation is not reversible and eq. (10) should only be used to model the compaction process when the differential pressure is a positive function of time. The formation factor is related to the porosity by the first Archie's law as mentioned above and where $m$ is a grain shape parameter typically comprised between 1.5 and 2.5 for clayey sandstones, with an average value around 2.0 (Vinegar $\&$ Waxman 1984). Therefore we assume that $m$ does not change much with the differential pressure and the relationship between the formation factor and the differential pressure is given by.

$F=\left[\phi_{0} \exp \left(-\beta_{m} P_{d}\right)\right]^{-m}$,

$F=F_{0} \exp \left(m \beta_{m} P_{d}\right)$.

where $F_{0}=\phi_{0}{ }^{-m}$ (Archie's law in the reference state). The other parameters in eqs (3)-(5) do not depend on the porosity and therefore are constant with respect to changes in the differential pressure. For the normalized chargeability and the surface conductivity, we need an expression between the bulk pore space tortuosity (defined by the ratio $F \phi$ ) and the differential pressure. Combining eqs (10) and (12), we easily obtain the following expression for the bulk tortuosity defined by the product between the formation factor and the connected porosity,

$F \phi=F_{0} \phi_{0} \exp \left[(m-1) \beta_{m} P_{d}\right]$.

It follows that the normalized chargeability follows for instance the following dependence with the differential pressure,

$M_{n}=M_{n}^{0} \exp \left[-(m-1) \beta_{m} P_{d}\right]$, 
Table 9. Evolution of the porosity variations with the differential pressure.

\begin{tabular}{lcccrc}
\hline$P_{d}(\mathrm{MPa})$ & $\mathrm{BB}-\mathrm{H} 3$ & $\mathrm{BR}-\mathrm{H} 2$ & $\mathrm{CG}-\mathrm{H} 3$ & $\mathrm{CT}-\mathrm{H} 1$ & 0.16540 \\
\hline 3.4474 & 0.18980 & 0.20550 & 0.26010 & 0.16390 & 0.15680 \\
5.1711 & 0.18860 & 0.20410 & 0.25740 & 0.16310 & 0.15630 \\
6.8948 & 0.18780 & 0.20340 & 0.25630 & 0.16200 & 0.15610 \\
10.342 & 0.18700 & 0.20230 & 0.25480 & 0.16130 & 0.15510 \\
13.790 & 0.18630 & 0.20160 & 0.25360 & 0.15980 \\
20.684 & 0.18540 & 0.20030 & 0.25160 & 0.15460 \\
\hline
\end{tabular}

Table 10. Reference porosity and apparent or effective compressibility coefficient obtained from the porosity versus differential pressure analysis.

\begin{tabular}{lcc}
\hline Sample & $\phi_{0}(-)$ & $\beta_{m}\left(\mathrm{~Pa}^{-1}\right)$ \\
\hline BB-H3 Berea (Buff) Sandstone & 0.1899 & $12.7 \times 10^{-10}$ \\
BR-H2 Berea Sandstone & 0.2057 & $13.9 \times 10^{-10}$ \\
CG-H3 Castlegate Sandstone & 0.2602 & $17.5 \times 10^{-10}$ \\
CT-H1 Carbon Tan Sandstone & 0.1656 & $18.5 \times 10^{-10}$ \\
NU-H2 Nugget Sandstone & 0.1572 & $11.3 \times 10^{-10}$ \\
\hline
\end{tabular}

Table 11. Cole-Cole relaxation time and pore size. The pore size is determined from the permeability reported in Table 1 and the formation factor determined from the porosity using the classical Archie's law $F=\phi^{-2}$. The equation is $\Lambda=(8 F k)^{1 / 2}$. The pore size $r$ is determined from NMR data.

\begin{tabular}{lccc}
\hline Sample & $\tau_{0}(-)$ & $\Lambda(\mu \mathrm{m})$ & $r(\mu \mathrm{m})$ \\
\hline 100u-GB Glass beads & 0.2092 & 31.5 & 3.62 \\
BB-H3 Berea (Buff) Sandstone & 1.2922 & 7.82 & 1.21 \\
BR-H2 Berea Sandstone & 0.6779 & 6.47 & 0.99 \\
CG-H3 Castlegate Sandstone & 2.94 & 10.84 & 1.03 \\
CT-H1 Carbon Tan Sandstone & 0.063 & 4.29 & 0.56 \\
NU-H2 Nugget Sandstone & 0.450 & 6.67 & 0.49 \\
\hline
\end{tabular}

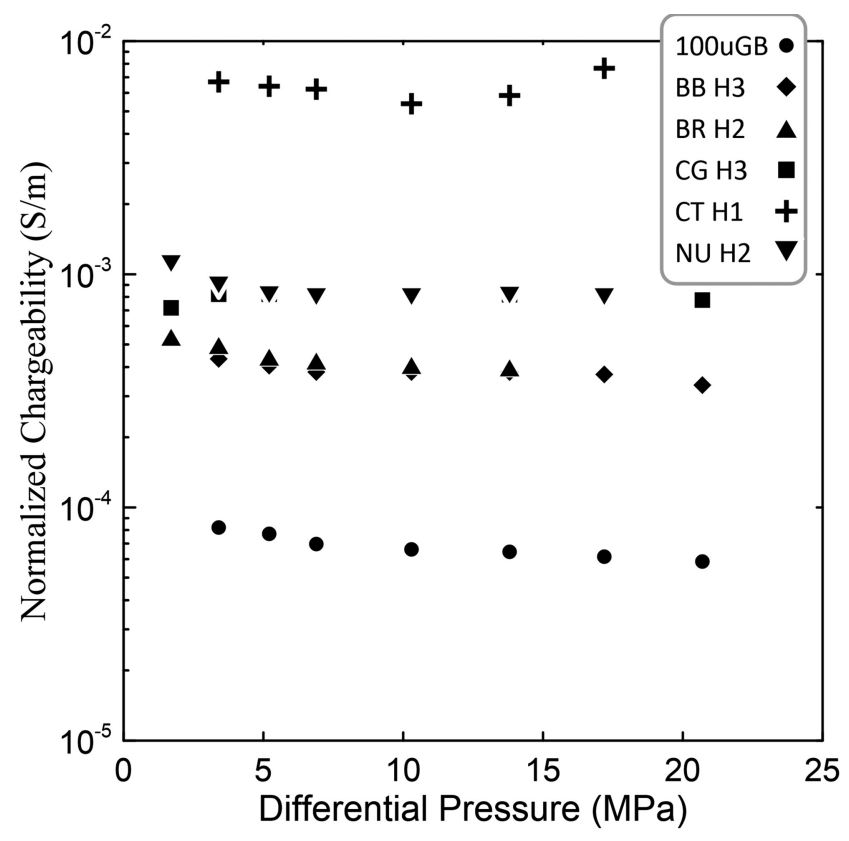

Figure 13. Evolution of the normalized chargeability as a function of the differential pressure (in $\mathrm{MPa}$ ). The plain lines correspond to the fit of the data with the normalized chargeability/differential stress constitutive relationship described in the main text. The two fitting parameters (initial porosity and compressibility coefficient) are provided on the figure. Normalized chargeability is calculated from In-phase conductivities 1.46 and $750 \mathrm{~Hz}$.

where $M_{n}^{0}$ denotes the initial value of the normalized chargeability in absence of differential stress. A similar equation can be written

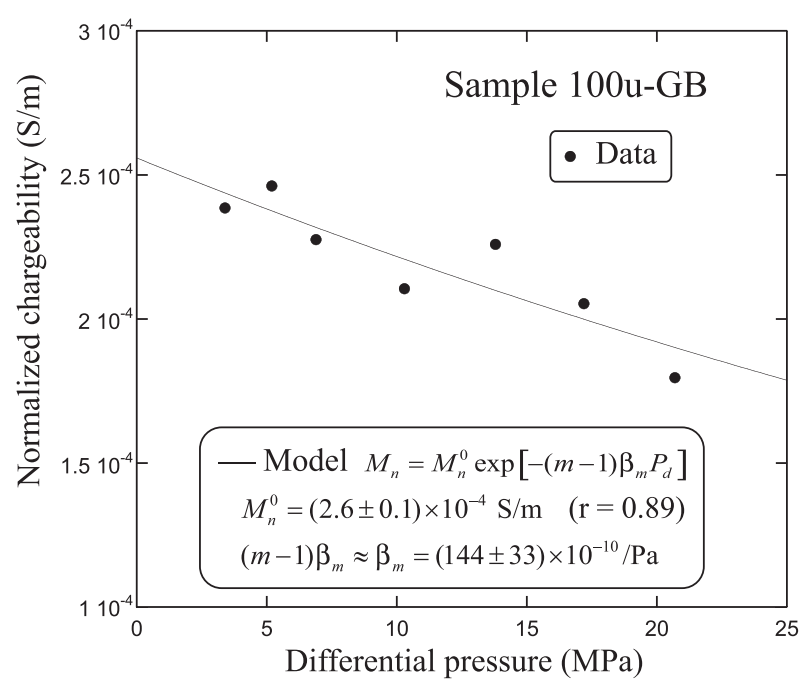

Figure 14. Evolution of the normalized chargeability as a function of the differential pressure (in MPa). The plain lines correspond to the fit of the data with the normalized chargeability/differential stress constitutive relationship described in the main text. The two fitting parameters (initial porosity and compressibility coefficient) are provided on the figure.

for the instantaneous conductivity when the conduction process is dominated by the surface conductivity.

\section{MATERIAL AND METHODS}

\subsection{Samples and experiments}

We use five outcrop sandstone samples and one sandstone analog constructed from fused glass beads. The five sandstone samples 


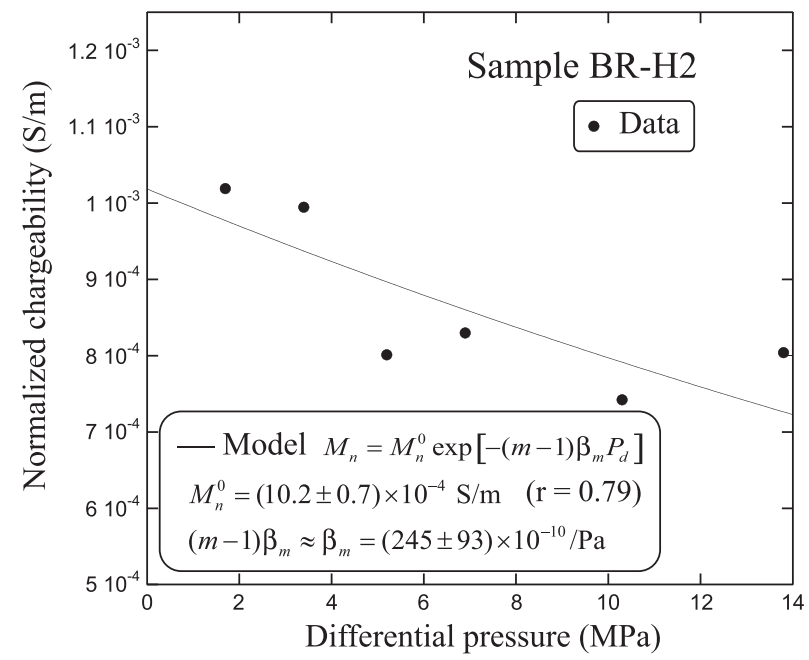

Figure 15. Evolution of the normalized chargeability as a function of the differential pressure (in $\mathrm{MPa}$ ). The plain lines correspond to the fit of the data with the normalized chargeability/differential stress constitutive relationship described in the main text. The two fitting parameters (initial porosity and compressibility coefficient) are provided on the figure.

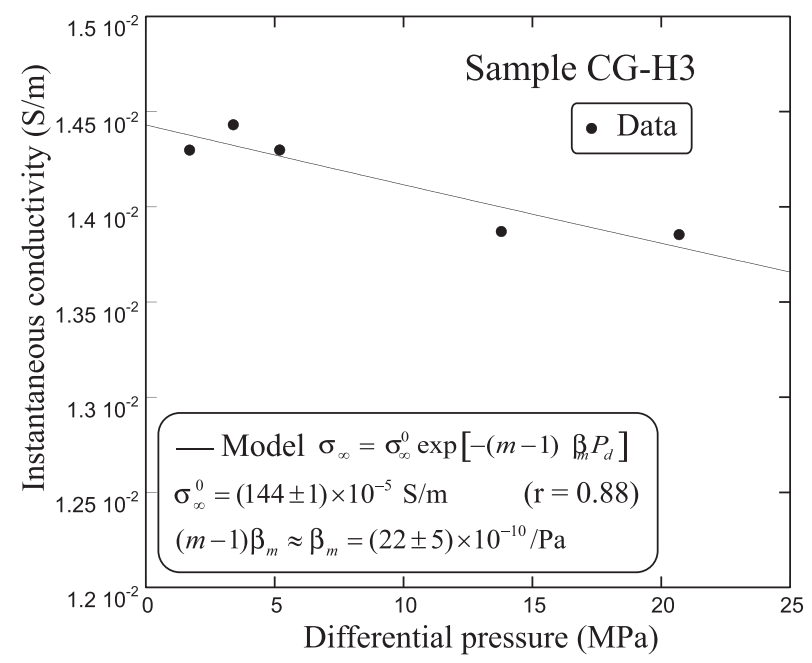

Figure 16. Evolution of the instantaneous conductivity as a function of the differential pressure (in MPa). The plain lines correspond to the fit of the data with the instantaneous conductivity/differential stress constitutive relationship described in the main text under the assumption that the response is dominated by surface conductivity. The two fitting parameters (initial value of the instantaneous conductivity and compressibility coefficient) are provided on the figure.

belong to different geological formations (their properties and mineralogical compositions are reported in Tables 1 and 2. The samples were visually inspected to select only samples with no major fractures or cracks. One way to bypass any complications caused by the uniqueness of natural rocks is to use synthetic porous media for which homogeneity, grain shape, grain size and composition can be better constrained. Our sandstone analog was built from glass beads. The $0.1 \mathrm{~mm}$ diameter glass beads used to construct the sandstone analog sample were composed of soda lime ( 72 per cent by weight $\mathrm{SiO}_{2}, 13$ per cent $\mathrm{Na}_{2} \mathrm{O}, 9$ per cent $\mathrm{CaO}, 3.4$ per cent $\mathrm{MgO}$, 2 per cent $\mathrm{Al}_{2} \mathrm{O}_{3}, 0.5$ per cent $\mathrm{K}_{2} \mathrm{O}$ and 0.1 per cent $\mathrm{Fe}_{2} \mathrm{O}_{3}$ ) with grain size deviation of $0.09-0.15 \mathrm{~mm}$ and roundness of $90-95$ per cent. The beads were placed inside of a cylindrical mold with a flat

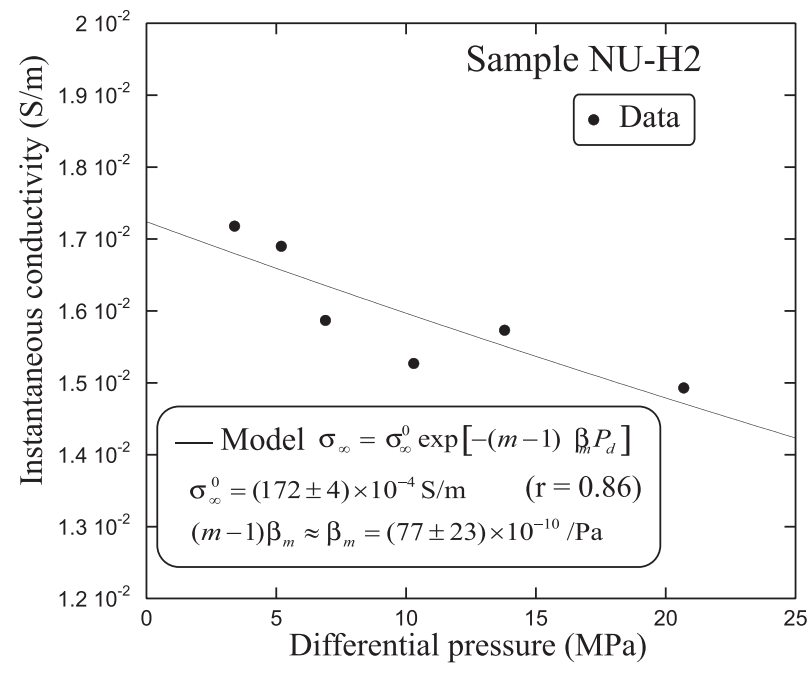

Figure 17. Evolution of the instantaneous conductivity as a function of the differential pressure (in MPa). The plain lines correspond to the fit of the data with the instantaneous conductivity/differential stress constitutive relationship described in the main text under the assumption that the response is dominated by surface conductivity. The two fitting parameters (initial value of the instantaneous conductivity and compressibility coefficient) are provided on the figure.

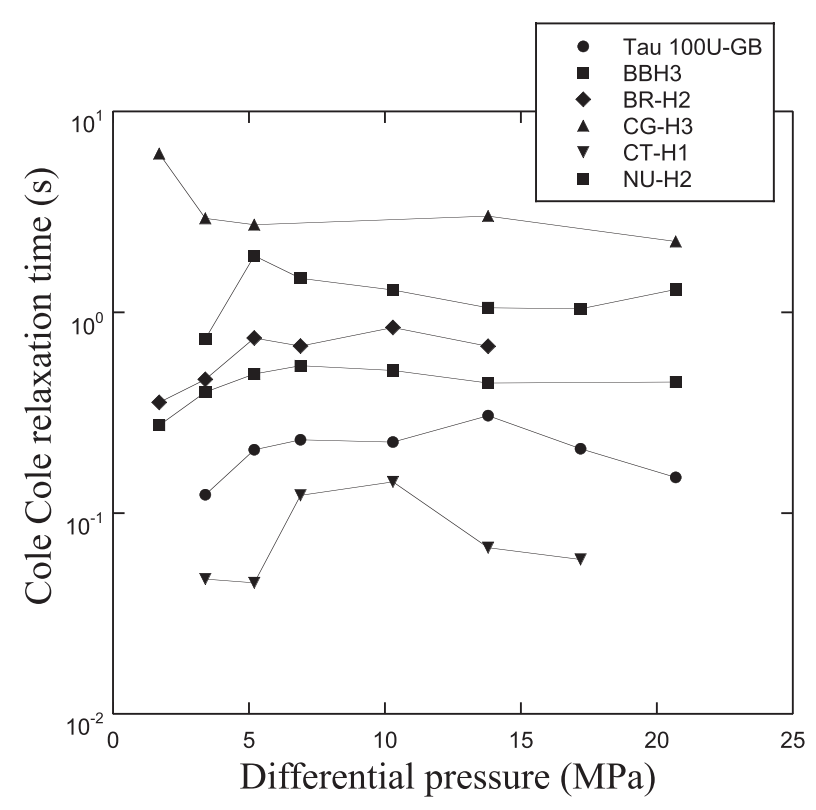

Figure 18. Evolution of the relaxation time as a function of the differential pressure (in MPa). The plain lines correspond are just guide to the eyes. Some samples show an increase of the Cole-Cole relaxation time with the differential pressure while some other samples show a decrease of Cole-Cole relaxation time with the differential pressure.

base and placed inside of a furnace for a pre-determined time. After allowing the sample to cool, a steel rod was used to push the sample out of the mold. The mold itself needs to be able to withstand high temperatures without deforming or bounding to the glass. We used a mold made of an alloy steel with melting temperatures between 1300 and $1500{ }^{\circ} \mathrm{C}$.

The low frequency conductivity measurement uses Ohm's law to characterize the resistivity properties of a rock sample using a socalled 4-electrodes method. The end cap current electrodes A and B 


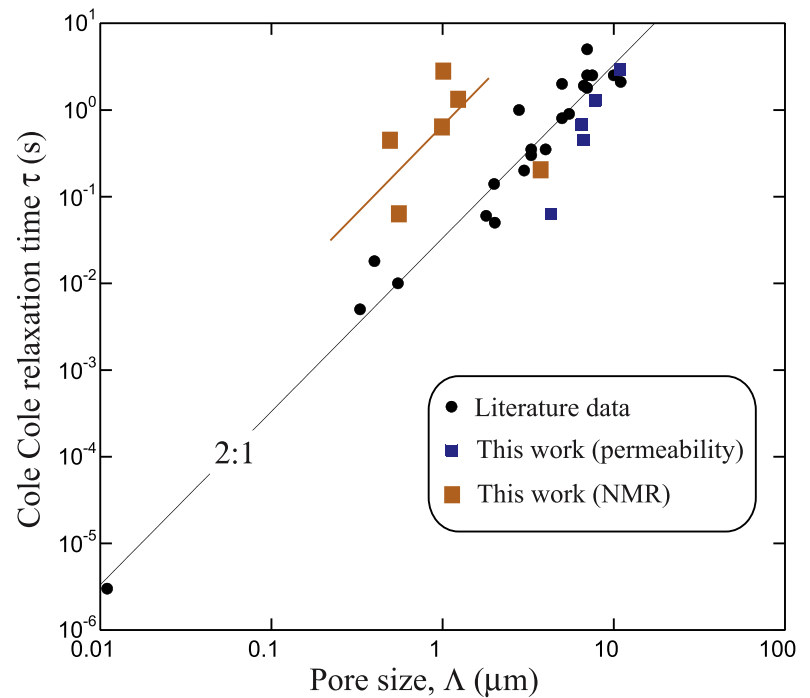

Figure 19. Cole-Cole relaxation time versus pore size. The plain line corresponds to the fit of the data with the equation $\tau_{0}=\Lambda^{2} /\left(2 D_{(+)}^{S}\right)$ with $D_{(+)}^{S}=15 \times 10^{-12} \mathrm{~m}^{2} \mathrm{~s}^{-1}$ (equivalent to a mobility for the counterions of $\left.5.8 \times 10^{-10} \mathrm{~m}^{2} \mathrm{~s}^{-1} \mathrm{~V}^{-1}\right)$. The black filled circles are the data from the literature (Scott \& Barker 2003, Revil 2013; Lesmes \& Frye 2001, Comparon 2005, Revil et al. 2014). The blue filled squares correspond to the five clayey sandstones used in this study at ambient pressure with the pore size $\Lambda$ determined from the (measured) permeability $k$ according to $k=\Lambda^{2} / 8 F$. The red filled squares correspond to the pore sizes determined by the NMR data.

(Fig. 3) are $1.5 \mathrm{~cm}$ diameter. The side (voltage) electrodes $\mathrm{M}$ and $\mathrm{N}$ are along the length of the core. We have multiple pairs of $\mathrm{M}$ and $\mathrm{N}$ electrodes in line with the side of the core. The end cap electrodes are made of brass while the side ones correspond to $2 \mathrm{~mm} \mathrm{Ag} / \mathrm{AgCl}$ electrodes (Fig. 3). For each experiment, we replaced the voltage electrodes by new ones. An impedance meter (ZEL-SIP04-V02) records the resistivity and the phase angle in the frequency sweep from $0.2 \mathrm{mHz}$ to $12 \mathrm{kHz}$. From the data, we determined the in-phase and quadrature components of the complex conductivities as a function of the differential pressure. We consider in the following that the geometric factor used to convert the recorded impedance to the complex conductivity is stress independent. Since the geometrical factor depends on the distance between the two voltage electrodes, and since this distance change with the deformation of the core samples, we expect the geometrical factor to be stress dependent. That said, we have checked here that because of the small variations of the deformation of the core samples, this effect can be neglected 'Appendix A).

\subsection{Porosity and permeability measurements}

The porosity and permeability measurements were done with a $\mathrm{MS}^{\mathrm{TM}}-300$ Automated permeameter, which is an unsteady state pressure decay permeameter and porosimeter. The dual-gas mode allows permeability estimates for core samples with permeability smaller than $10^{-17} \mathrm{~m}^{2}$. This instrument uses an integrated form of the combined Darcy, Klinkenberg and Forchheimer equations to estimate permeability from $>15 \times 10^{-12} \mathrm{~m}^{2}$ to $<0.05 \times 10^{-18}$. Pore Volume measurements are made using Boyle's Law method combined with a calibration technique. The apparatus uses helium as its measurement fluid. It is difficult to estimate how accurate are the porosity measurements reported in the present work.

\subsection{NMR measurements}

We used nuclear magnetic resonance (NMR) to characterize the mean pore size and the pore size distribution of the material. These measurements discussed below were performed before all pressure cycles. The NMR T2 response was used as a determination of pore size distribution (PSD) and raw magnetic decay data was inverted to the time domain as a time distribution from the inversion protocol developed by Lawson \& Hanson (1974) and Buttler et al. (1981). Inversion was performed for 200 time steps from 0.01 to $10000 \mathrm{~ms}$. The NMR used for this procedure was a $2 \mathrm{MHz}$ NMR from Magritek. Before the experiment was performed the equipment is tuned to the correct Larmor frequency of the saturating fluid and the background is captured at a signal-to-noise ratio of 200 to be subtracted after the experiment is performed. We used 10000 echoes to observe full signal decay and an experimental delay larger than or equal to three times the relaxation time to ensure full relaxation following the pulse sequence before repeating the measurement. Experimental signal-to-noise ratios of 100 were obtained for each experiment run.

NMR porosity determination was performed by measuring the bulk volume of the core using calipers and volume was recorded. NMR signal amplitudes of known fluid volumes were collected prior to data collection on the cores. Signal amplitude from the saturated core plugs was then used to determine volume of interstitial fluid by normalization with the known fluid volume standards and this value was divided by bulk volume to calculate porosity in each of the NMR runs.

\section{RESULTS}

\subsection{Complex conductivity spectra}

The complex conductivity spectra are shown in Figs 4-9. They are fitted with the Cole-Cole function described in Appendix B. The Cole-Cole parameters are reported for each core sample in Tables 38 . The induced polarization characteristics correspond to the lowest Cole-Cole dispersion characterized by the label 1 in these tables. We will discuss only these Cole-Cole parameters below. For sample $100 \mathrm{u}-\mathrm{GB}$, it is difficult to get the Cole-Cole parameters since the relaxation peak seems to occur at very low frequencies (below 1 $\mathrm{Hz}$ ) and we do not have complex conductivity measurements for this core sample at these low frequencies. All the samples exhibit a well-defined polarization peak and are reasonably well-fitted by a Cole-Cole parametric function.

\subsection{Cole-Cole exponent and chargeability}

The Cole-Cole exponent $c$ is shown as a function of the differential pressure in Fig. 10. We observe that the Cole-Cole exponent does not vary a lot with the differential stress indicated that the distribution of the pore sizes is essentially preserved through the compaction process. We also note that the Cole-Cole exponent is close to 0.5 , the highest value usually reached by the Cole-Cole exponent as pointed out by Revil et al. (2014). This implies in turn that the pore size distribution of these sandstones is very narrow. This is confirmed by NMR relaxation distributions indicating narrow pore size distributions for the investigated sandstones.

The evolution of the chargeability $M$ as a function of the differential pressure is shown in Fig. 10. We observe no specific trend between these two parameters. In order to go a bit further into the interpretation of the results of Fig. 11, we need to come back to the 

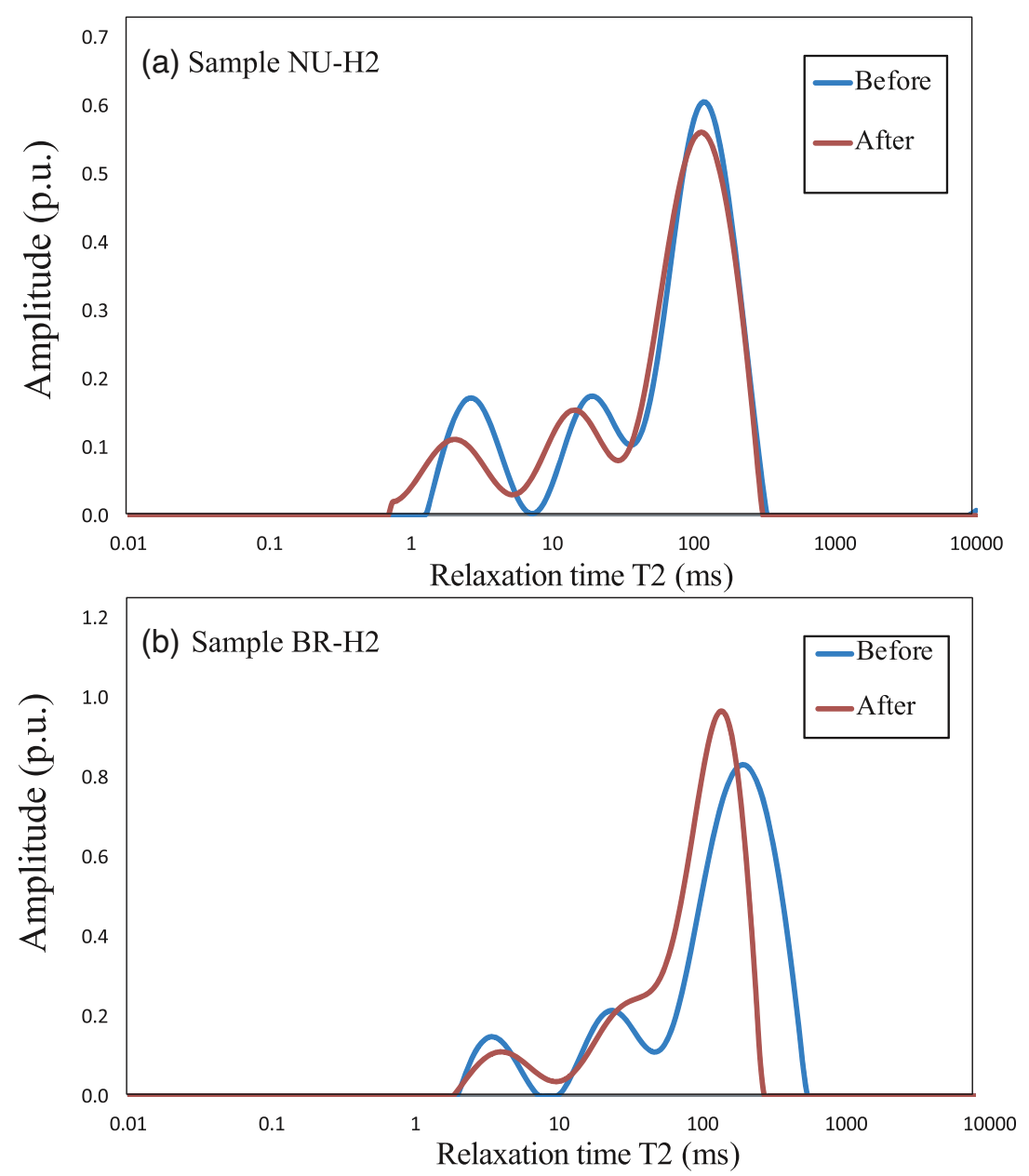

Figure 20. Comparison of the NMR T2 spectra before and after the deformation tests for samples NU-H2 and BR-H2. The small change in the T2 relaxation times distributions implies that the pore size change is relatively modest in these experiments.

modelling. The chargeability is defined as

$M=\frac{\sigma_{\infty}-\sigma_{0}}{\sigma_{\infty}}$.

From eqs (3) and (4), we obtain the following expression for the chargeability

$M=\frac{\rho_{g} \lambda \mathrm{CEC}}{\phi \sigma_{w}+\rho_{g} B \mathrm{CEC}}$.

It is interesting to note that when surface conductivity dominates the bulk conductivity due to the pore water salinity, we have

$\lim _{\sigma_{w}<<\frac{\rho_{g} B C E C}{\phi}} M=\frac{\lambda}{B}=R$,

where the dimensionless number $R$ is equal to $9 \times 10^{-2}$. In other words, $M$ is necessarily smaller or equal to $\mathrm{R}$ except in presence of metallic particles such as pyrite or magnetite. Disseminated metallic particles have a strong influence on induced polarization spectra (Pelton et al. 1978). In presence of pyrite, we have (Revil et al. 2015a,b),

$M=\frac{9}{2} \varphi_{m}+\frac{\rho_{g} \lambda \mathrm{CEC}}{\phi \sigma_{w}+\rho_{g} B \mathrm{CEC}}$ where $\varphi_{m}$ denotes the volumetric fraction of pyrite. And at low salinities we have in this case,

$M=\frac{9}{2} \varphi_{m}+R$

Therefore the presence of pyrite increases the chargeability beyond the highest possible value of $R$ in absence of metallic particles. With these results in mind and looking further at Fig. 11, we can reach the following conclusions. Sample NU-H2 has a chargeability above the maximum value allowed for metal-free sandstone, which means that it is likely to bear pyrite. Its mean chargeability is $\sim 0.135$, which implies a pyrite content of 1 per cent (vol.). Samples BB-H3, BR$\mathrm{H} 2$, CG-H3, and CT-H1 have reach the maximum value possible for metal free sandstones $\left(M=R=9 \times 10^{-2}\right)$, which in turn implies that their conductivity is dominated by surface conduction. This is consistent with the fact that these sandstones contains some clay minerals (see Table 2). Sample 100u-GB has a very small chargeability indicating that its conductivity is dominated by the conduction through the bulk pore space. This is consistent with the fact that this sandstone is totally clay-free since it was formed by sintering glass beads as explained above. 


\subsection{Porosity}

The porosity versus differential stress data are shown in Fig. 12 and reported in Table 9. They are fitted by eq. (9) and the two fitting parameters are reported in Table 10. The initial porosities are comprised between $0.26(\mathrm{CG}-\mathrm{H} 3)$ and $0.16(\mathrm{NU}-\mathrm{H} 2)$ while the values of the effective compressibility are in the range 11$19 \times 10^{-10} \mathrm{~Pa}^{-1}$. eq. (9) provides a very reasonable fit of the data.

\subsection{Instantaneous conductivity and normalized chargeability}

In Figs 13-17, we show how the normalized chargeability and the instantaneous conductivity behave with respect to the differential pressure. As expected, these two parameters decrease with the increase of the differential pressure because of the change of the porosity with the differential pressure. That said, the compressibility coefficient we found are substantially higher than for the porosity except for sample CG-H3. We have no explanation for this discrepancy.

\subsection{Cole-Cole relaxation time}

The variations of the Cole-Cole relaxation time with the differential pressure are shown in Fig. 18. We see small variations between these two parameters but the small trends are not consistent from one sample to the other. Generally speaking, the Cole-Cole relaxation time does not change with the differential pressure. This implies, in turn, from eq. (7) that the pore size has not been changing too much with the differential pressure inside the uncertainty associated with the estimate of the Cole-Cole relaxation times. Fig. 19 shows that the Cole-Cole relaxation time is related to the pore size determined from the permeability and the formation factor (Table 11). We see that our dataset is consistent with previous datasets showing a strong relationship between the Cole-Cole relaxation time and the pore size of the porous material.

\subsection{Comparison with NMR data}

The NMR data provides the smallest dimension of pore diameter by the assumption of a constant pore shape. This size, is smaller than the mean pore size in pores with larger aspect ratios like those we see in compressional systems. Thus, the slightly smaller predicted NMR pore sizes can be due to aspect ratios that are greater than 1 or the improper selection of the surface relaxivity parameter used to scale pore size distribution in the time domain to the size domain. The systematic difference observed in the NMR data could be explained by either of these phenomena. Fig. 19 shows that the Cole-Cole relaxation time is related to the pore throat size determined from the NMR data. The data shows a fair relationship between the ColeCole relaxation time and the pore size from NMR. This indicates that the two parameters are somehow interrelated and that the relaxation times depend on the square of the pore sizes. Fig. 20 shows that the T2 relaxation time distributions from NMR data does not change too much during the deformation tests. This indicates again that the pore size distributions have not change too much in these experiments.

\section{CONCLUSION}

We have performed compaction experiments in which six sandstones (including an artificial sandstone obtained by sintering glass beads) are investigated in the differential differential pressure range 3-20.7 MPa. Complex conductivity spectra were measured in the frequency range $0.2 \mathrm{mHz}$ to $12 \mathrm{kHz}$ and fitted with a Cole-Cole complex conductivity model. In addition porosity was investigated as a function of the differential pressure. Both the porosity and the formation factor were related to the differential pressure through a simple exponential constitutive equation. The following conclusions were reached:

(1) The Cole-Cole exponent and the chargeability are essentially independent of the differential pressure. The high value of the ColeCole exponent is usually close to 0.5 indicating a narrow pore size distribution, which is confirmed by NMR measurements. For most of the core samples, the chargeability is close to 0.09 (actually in the range between 0.075 and 0.12 with the exception of the Nugget sample) indicating that the conductivity is dominated by surface conduction.

(2) The porosity and the instantaneous conductivity both decrease with the differential stress because of compaction. The relationship between these parameters takes the form of an exponential law.

One way to expand the present work would be to perform numerical modeling using discrete element technique (such as used by Niu et al. 2017, for electrical conductivity) or network models (such as used by Maineult et al. 2017, to model complex conductivity). Such step is required to better elucidate the micro-mechanisms of polarization and decipher how the changes in the effective stress tensor can modify the complex conductivity tensor during the deformation of porous rocks.

\section{ACKNOWLEDGEMENTS}

We would like to thank Andre Panfiloff and Liwei Ou for their help with the experimental work and the colleagues of the OCLASSH Consortium and Center for Rock Abuse, the petroleum engineering department for fruitful discussions. Mark Kittridge and HESS for their support and for the samples and Qifei Niu for helpful suggestions and discussions. A. Revil thanks the French National Research Agency (ANR) through the HYDROGEODAM project under grant no. ANR-17-CE06-0016, for funding his contribution. We thank the Editor, Dr Alexis Maineult and the referees, Dr Matthias Bücker and an anonymous referee, for their time and fruitful suggestions.

\section{REFERENCES}

Archie, G.E., 1942. The electrical resistivity log as an aid in determining some reservoir characteristics, Trans. AIME, 146, 54-62.

Binley, A., Hubbard, S.S., Huisman, J.A., Revil, A., Robinson, D.A., Singha, K. \& Slater, L.D., 2015. The emergence of hydrogeophysics for improved understanding of subsurface processes over multiple scales, Water Resour. Res., 51, 3837-3866.

Börner, F.D., 1992. Complex conductivity measurements of reservoir properties, in Proceedings of the Third European Core Analysis Symposium, Paris, pp. 359-386.

Buttler, J.P., Reeds, J.A. \& Dawson, S.V., 1981. Estimating solution of first kind integral equations with non-negative constraints and optimal smoothing, SIAM J. Numer. Anal., 18, 381-397.

Bücker, M. \& Hördt, A., 2013a. Long and short narrow pore models for membrane polarization, Geophysics, 78(6), E299-E314.

Bücker, M. \& Hördt, A., 2013b. Analytical modeling of membrane polarization with explicit parametrization of pore radii and the electrical double layer, Geophys. J. Int., 194, 804-813. 
Cole, K.S. \& Cole, R.H., 1941. Dispersion and absorption in dielectrics. I. Alternating current characteristics, J. Chem. Phys., 9, 341-351.

Comparon, L., 2005. Etude expérimentale des propriétés électriques et diélectriques des matérieux argileux consolidés, PhD thesis, Institut de Physique du Globe de Paris, 400pp.

Duvillard, P.A., Revil, A., Soueid Ahmed, A., Qi, Y., Coperey, A. \& Ravanel, L., 2018. Three-dimensional electrical conductivity and induced polarization tomography of a rock glacier, J. geophys. Res., 123(11), 9528-9554.

Ghorbani, A., Revil, A., Coperey, A., Soueid Ahmed, A., Roque, S., Heap, M.J., Grandis, H. \& Viveiros, F., 2018. Complex conductivity of volcanic rocks and the geophysical mapping of alteration in volcanoes, J. Volc. Geotherm. Res., 357, 106-127.

Lawson, C.L. \& Hanson, R.J., 1974. Solving Least Square Problems, Prentice-Hall.

Lesmes, D.P. \& Frye, K.M., 2001. Influence of pore fluid chemistry on the complex conductivity and induced polarization responses of Berea sandstone, J. geophys. Res., 106(B3), 4079-4090.

Maineult, A., Revil, A., Camerlynck, C., Florsch, N. \& Titov, K., 2017. Upscaling of spectral induced polarization response using random tube networks, Geophys. J. Int., 209(2), 948-960.

Mosegaard, K. \& Tarantola, A., 1995. Monte Carlo sampling of solutions to inverse problems, J. geophys. Res., 100(B7), 12431-12447.

Niu, Q., Revil, A. \& Saidian, M., 2016. Salinity dependence of the complex surface conductivity of the Portland sandstone, Geophysics, 81(2), D125D140.

Niu, Q. \& Revil, A., 2016. Connecting complex conductivity spectra to mercury porosimetry of sedimentary rocks, Geophysics, 81(1), E17-E32,

Niu, Q., Revil, A., Li, Z. \& Wang, Y.-H., 2017. Relationship between electrical conductivity anisotropy and fabric anisotropy in granular materials during drained triaxial compressive tests: a numerical approach, Geophys. J. Int., 210(1), 1-17.

Pelton, W., Ward, S., Hallof, P., Sill, W. \& Nelson, P., 1978. Mineral discrimination and removal of inductive coupling with multifrequency IP, Geophysics, 43, 588-609.

Qi, Y., Soueid Ahmed, A., Revil, A., Ghorbani, A., Abdulsamad, F., Florsch, N. \& Bonnenfant, J., 2018. Induced polarization response of porous media with metallic particles - Part 7. Detection and quantification of buried slag heaps, Geophysics, 83(5), E277-E291.

Razilov, I.A. \& Dukhin, S.S., 1995. Simultaneous influence of concentration polarization of the diffuse layer and polarization of the Stern layer according to the mechanism of bound counterions at arbitrary magnitudes of the relaxation parameter, Colloid J., 57(3), 364-371 [translated from Kolloidnyi Zhurnal, 57(3), 391-399].

Revil, A., 2013. Effective conductivity and permittivity of unsaturated porous materials in the frequency range $1 \mathrm{mHz}-1 \mathrm{GHz}$, Water Resour. Res., 49, 306-327.

Revil, A. \& Florsch, N., 2010. Determination of permeability from spectral induced polarization data in granular media, Geophys. J. Int., 181, 14801498.

Revil, A., Grauls, D. \& Brévart, O., 2002. Bulk mechanical compaction of sand shale mixtures, J. geophys. Res., 107(B11), 2293.

Revil, A., Koch, K. \& Holliger, K., 2012. Is it the grain size or the characteristic pore size that controls the induced polarization relaxation time of clean sands and sandstones? Water Resour. Res., 48, W05602.

Revil, A., Florsch, N. \& Camerlynck, C., 2014. Spectral induced polarization porosimetry, Geophys. J. Int., 198, 1016-1033.

Revil, A., Florsch, N. \& Mao, D., 2015a. Induced polarization response of porous media with metallic particles - Part 1: a theory for disseminated semiconductors, Geophysics, 80(5), D525-D538.

Revil, A., Abdel Aal, G.Z., Atekwana, E.A., Mao, D. \& Florsch, N., 2015 b. Induced polarization response of porous media with metallic particles - Part 2. Comparison with a broad database of experimental data, Geophysics, 80(5), D539-D552.

Revil, A. et al., 2017. Complex conductivity of soils, Water Resour. Res., 53(8), 7121-7147.

Revil, A., Coperey, A., Mao, D., Abdulsamad, F., Ghorbani, A., Rossi, M. \& Gasquet, D., 2018a. Induced polarization response of porous media with metallic particles - Part 8. Influence of temperature and salinity, Geophysics, 83(6), 1-22.

Revil, A., Coperey, A., Deng, Y., Cerepi, A. \& Seleznev, N., 2018b. Complex conductivity of tight sandstones, Geophysics, 83(2), E55-E74.

Revil, A, Soueid Ahmed, A. \& Matthai, S., 2018c. Transport of water and ions in partially water-saturated porous media. Part 3. Electrical conductivity. Adv. Water Res., 121, 97-111.

Robinson, J., Slater, L., Weller, A., Keating, K., Robinson, T., Rose, C. \& Parker, B., 2018. On permeability prediction from complex conductivity measurements using polarization magnitude and relaxation time, Water Resour. Res., 54, 3436-3452.

Rosen, L.A. \& Saville, D.A., 1991. Dielectrical spectroscopy of colloidal dispersions: comparisons between experiment and theory, Langmuir, 7, 36-42.

Rosen, L.A., Baygents, J.C. \& Saville, D.A., 1993. The interpretation of dielectric response measurements on colloidal dispersions using the dynamic Stern layer model, J. Chem. Phys., 98(5), 4183-4194.

Scott, J. \& Barker, R., 2003. Determining pore-throat size in Permo-Triassic sandstones from low-frequency electrical spectroscopy, Geophys. Res. Lett., 30(9), 1450.

Sen, P.N., Goode, P.A. \& Sibbit, A., 1988. Electrical conduction in clay bearing sandstones at low and high salinities, J. appl. Phys., 63(10), 4832-4840.

Van Voorhis, G.D., Nelson, P.H. \& Drake, T.L., 1973. Complex resistivity spectra of porphyry copper mineralization, Geophysics, 38(1), 49-60.

Vinegar, H.J. \& Waxman, M.H., 1984. Induced polarization of shaly sands, Geophysics, 49, 1267-1287.

Weller, A., Nordsiek, S. \& Debschütz, W., 2010. Estimating permeability of sandstone samples by nuclear magnetic resonance and spectral-induced polarization, Geophysics, 75, E215-E226.

Weller, A., Slater, L., Binley, A., Nordsiek, S. \& Xu, S., 2015. Permeability prediction based on induced polarization: Insights from measurements on sandstone and unconsolidated samples spanning a wide permeability range, Geophysics, 80, D161-D173.

Weller, A., Zhang, Z., Slater, L., Kruschwitz, S. \& Halisch, M., 2016. Induced polarization and pore radius - a discussion, Geophysics, 81, 519526.

\section{APPENDIX A: GEOMETRICAL FACTOR DEPENDENCE ON STRESS}

During compressional loading, the porosity of the cylindrical core sample decreases and both its length and diameter change. The porosity of sample during loading can be calculated as a function of the reference porosity $\phi_{0}$ and the differential pressure $P_{d}=\sigma-p$ by eq. (10). The porosity is given by $\phi=V_{n p} / V_{1}$, where $V_{n p}$ and $V_{1}$ denote the volume of pore space and total volume of sample after loading, respectively. eq. (A2) yields:

$\phi=\frac{V_{o p}-\Delta V}{V_{1}}=\frac{V_{0} \phi_{0}-\left(V_{0}-V_{1}\right)}{V_{1}}=1+\frac{V_{0}\left(\phi_{0}-1\right)}{V_{1}}$,

where $V_{o p}$ is the volume of pore space before loading, $\Delta V$ the change of volume, and $V_{0}$ the initial volume. The geometrical factor is obtained when the electrodes A and B are on the end-faces of the cylindrical core sample and the electrodes $\mathrm{M}$ and $\mathrm{N}$ separated by a distance $L$ on its side (Fig. 3). In this case, the geometrical factor can be written:

$K=\frac{L}{A}=\frac{4 L}{\pi d^{2}}$,

where $A$ and $L$ denote the cross-section area and length of the cylindrical core sample between $\mathrm{M}$ and N. $K$ can be expressed as a function of the initial geometrical factor, $K_{0}$, by

$\frac{K}{K_{0}}=\frac{L}{L_{0}}\left(\frac{d_{0}}{d}\right)^{2}$. 
Replacing eqs (A3)-(A5) yield

$\frac{K}{K_{0}}=\frac{1-\phi}{1-\phi_{0}}\left(\frac{L}{L_{0}}\right)^{2}$,

$\frac{K}{K_{0}}=\frac{1-\phi_{0} \exp \left(-\beta_{m} P_{d}\right)}{1-\phi_{0}}\left(\frac{L}{L_{0}}\right)^{2}$.

Using the length variations of the core samples, the initial porosity and compressibilities of the core samples (Table 10), the relative variation of the geometrical factor is in the range $0.4-1.4$ per cent, and therefore negligible.

\section{APPENDIX B: DOUBLE COLE-COLE PARAMETRIZATION AND INVERSION}

In order to fit the experimental data, we use a double Cole-Cole model written as,

$\sigma *=\sigma_{\infty}\left(1-\frac{M_{1}}{1+\left(i \omega \tau_{1}\right)^{c_{1}}}-\frac{M_{2}}{1+\left(i \omega \tau_{2}\right)^{c_{2}}}\right)$, where $\sigma *$ denotes the complex conductivity, $\omega$ is the angular frequency, $\sigma_{\infty}$ denotes the instantaneous conductivity (in $\mathrm{S} \mathrm{m}^{-1}$ ), $M_{1}$ and $M_{2}$ (dimensionless) corresponds to the chargeabilities associated with the two polarization mechanisms, $c_{1}$ and $c_{2}$ (dimensionless) are the two Cole-Cole exponents (dimensionless), and $\tau_{1}$ and $\tau_{2}$ (in s) are the (relaxation) time constants. The low frequency Cole-Cole model is used to model the induced polarization of the insulating grains coated by the electrical double layer (the index 1 , and 2 refer to lower and higher frequency dispersions, respectively). The complex conductivity spectra discussed in the main text are inverted using this double Cole-Cole model and the non-linear iterative method proposed by Mosegaard \& Tarantola (1995) based on a Monte Carlo Markov Chain (MCMC) sampling algorithm. The approach is described in Qi et al. (2018) and will not be repeated here. In the main text, we will discuss only the low frequency polarization mechanism. 